\title{
Performance Analysis of Mobile Broadband Technologies and $5 G$ Trends and Beyond Networks in Malaysia
}

This paper was downloaded from TechRxiv (https://www.techrxiv.org).

\section{LICENSE}

CC BY 4.0

SUBMISSION DATE / POSTED DATE

$21-12-2021 / 28-12-2021$

\section{CITATION}

Shayea, Ibraheem; Azmi, Marwan; Ergen, Mustafa (2021): Performance Analysis of Mobile Broadband Technologies and 5G Trends and Beyond Networks in Malaysia. TechRxiv. Preprint. https://doi.org/10.36227/techrxiv.17307110.v1

$\mathrm{DOI}$ 


\title{
Performance Analysis of Mobile Broadband Technologies and 5G Trends and Beyond Networks in Malaysia
}

\author{
Ibraheem Shayea ${ }^{1}$, Marwan Hadri Azmi ${ }^{2}$, Mustafa Ergen ${ }^{1}$, Yousef Ibrahim Daradkeh ${ }^{4}$, Ayman \\ A. El-Salah ${ }^{3}$, Chua Tien $\mathrm{Han}^{2}$, Arsany Arsad ${ }^{2}$, Tharek Abd. Rahman ${ }^{2}$, Dalia Nandi ${ }^{5}$
}

\begin{abstract}
This paper analysis and investigate the performance of Mobile Broadband (MBB) cellular networks based on the drive tests for suburban areas (at four states) in Malaysia. The data were collected from three main national Mobile Network Operators (MNOs) by using unbranded Samsung Galaxy S6 smartphone handsets, while the period of data collection was between January and February. Two MBB services were considered which are the video streaming and web browsing. For each MNO, the performance data of one MBB service was collected through one a dedicated smartphone. One smartphone was used to browse three different webpages, and One smartphone was employed to stream two YouTube videos with two different resolutions. The study considered four MBB Key Performance Indicators (KPIs), namely: latency, coverage, speed and satisfaction. As per the results, the performance of Fourth Generation (4G) is found superior than that of Third Generation (3G) networks. For instance, a vMOS score of above 3.3 was achieved by 4G networks for MBB video-streaming service, while, score of below 2.6 was attained by $3 G$ networks across all the four studied areas. In addition, it was observed that an enhancement factor of up to 2.86 and 2.83 in download speed was presented by $4 \mathrm{G}$ technology in case of video streaming and web page browsing respectively as compared to 3G technology. Examining the performance of current MBB networks is supportive before the deployment of the 5G network. The efficient development of 5G networks in Malaysia can be realized through these study findings, where the existing 4G infrastructures will contribute to supporting the 5G and $6 \mathrm{G}$ networks.
\end{abstract}

Index Terms_Mobile Broadband, MBB, Mobile Networks, 3G, 4G, 5G, 6G, Performance Evaluation, network planning, future Mobile, Drive Test, Suburban, Coverage, Latency, and Throughput.

\section{INTRODUCTION}

$\mathrm{T}$ he past decade has witnessed several new technological advancements in mobile communication systems. Different technologies, services, and applications have been emerged in various environments leading to a massive increase in data traffic demands. These developments and requirements will be supported by the Fifth Generation $(5 \mathrm{G})$ of mobile communication technology and later one by $6 \mathrm{G}$ technology. Several improvements were promised to be

Manuscript received xxx 10, 2021; revised yyy 10, 2022; accepted zzz 10, 2022.

This research has been produced benefiting from the 2232 International Fellowship for Outstanding Researcher Program of TÜBiTAK (Project No: 118C276) conducted at Istanbul Technical University (ITU), Turkey. Meanwhile,
the authors would like to acknowledge the support provided by the Ministry of Higher Education Malaysia (MOHE) the authors would like to acknowledge the support provided by the Ministry of Higher Education Malaysia (MOHE)
under the Fundamental Research Grant Scheme (FRGS/1/2019/TK04/UTM/02/34). The work was also supported in

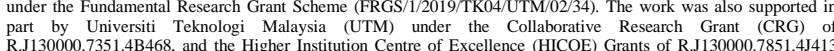
and R.J130000.7851.4J493

This paper is an expanded version from ett. 3697 paper published on, 31 July, City, Country. Corresponding author: Ibraheem Shayea \{e-mail: ibr.shayea@gmail.com\}

The authors Ibraheem Shayea and Mustafa Ergen are with Electronics and Communication Engineerin Department, Faculty of Electrical and Electronics Engineering, Istanbul Technical University (ITU), Turkey (e-mai ibr.shayea@gmail.com (shayea@itu.edu.tr, mustafaergen@itu.edu.tr). Marwan Azmi, Chua Tien Han, Arsany Arsa Teknologi Malaysia Johor Malaysia Yousef Ibrahim Daradkeh Department of Computer Engineering and Networks, College of Engineering at Wadi Addawasir, Prince Sattam Bin Abdulaziz University, KSA. Ayman A. ElSalah with Department of Electronics and Communication Engineering, College of Engineering, A'Sharqiya University (ASU), 400 Ibra, Oman. Dalia Nandi with ECE Department of Indian Institute of Information Technology (IIIT), Kalyani, West Bengal, India. provided by this new technology such as the quality of service, system capacity, coverage expansion, higher data rate, lower latency and other more mobile devices. Even though, there are several issues in the current MBB networks, such as the service interruption, poor internet connectivity and denial of service are some of the drawbacks or unsettled issues, which need to be addressed properly. One of the root causes of such issues is the poor network planning. The key performance indicators of the Third Generation (3G) and Fourth Generation (4G) networks need to be thoroughly investigated, so that these issues could be addressed in an effective manner. Hence the professionals will get basic information on the network performance, through which, improvement initiatives could be enabled. The high network performance, ubiquitous coverage and user Quality of Experience (QoE) are now being offered by the Mobile Broadband (MBB) Networks, which is of the primary interest for mobile network operators [1-5]. Thus, the engineers and researchers are inspired to upgrade the capabilities of MBB networks through new tools and technologies, which will play a significant role in the growth of mobile traffic volume and for a broad range of user devices and applications.

The evaluation of data offloading techniques to improve mobile networks depends upon the understanding of mobile data traffic demands. Furthermore, telecom companies can set subscription plans and timely plan allocation of network resources as a result of the dentition of a usage pattern. The gap between the users' ever-growing demands and expectations as well as the performance of the current MBB networks needs to be understood by the experts. After gaining an insight with this gap, the MBB networks can further be extended to address the challenges that leading to increase demand for larger network capacity, higher data rates and higher spectral efficiency as projected for future $5 \mathrm{G}$ cellular services. The rural, urban and suburban areas are having the broadband availability and its adoption at the different rates. As compared to metropolitan cities, the wireless technologies are generally accessible to suburbs vs regional areas with considerably lower data rates and less dense arrangements. In contrast, there is higher vehicle speed across the regional areas. Therefore, for effective network planning, researchers should perform wide-ranging measurements at different morphologies.

As compared to the wired networks, the MBB networks have highly challenging performance assessment. Because of the large number of factors affecting performance, the simplest test, i.e., a "speedtest- like" measurement of the single Transmission Control Protocol (TCP) download speed using a 
Hypertext Transfer Protocol (HTTP), may become insufficient to be explain the complete MBB networks. The measurement outcomes are influenced by the mobility, physical impairments, presence of Performance Enhancing Proxies (PEP) [6], variety of devices, different access network configurations, etc., and the overall picture becomes even complicated. When adopting performance calculations, a communal method is to depend on end users, and their devices, to run tests by browsing a website [7], or running a specific application [8]. For different mobile networks with different operators, one of the effective solutions to identify performance gaps or coverage holes is none other than the drive test.

The system level and link level are referred to as the two different levels or platforms [9][10]: on which the researchers carry out performance assessment of service quality in mobile networks. The first one deals with macroscopic aspects, for example, admission control, shadowing, handover, etc. Its aim is to evaluate the performance of network at the signal level, while, the characteristic of radio link transmission is managed by the other one at the bit level aiming to assess network performance. Furthermore, there is still a lack of study related to the performance evaluation of mobile networks.

In [11], researchers performed a comparative study and analysis on the network performance of four mobile operators in Nigeria. The network was evaluated by considering numerous key performance indicators (KPIs) specified by the Nigerian Communications Commission (NCC). One of the mobile operator's networks was fairly better as per the study findings and the network with the thorough information was preferred for optimization, the aim of which will be to enhance its performance attributes.

In [12], a research on the association among four Long Term Evolution (LTE) measurements namely; the received signal strength indicator (RSSI), referenced signal received quality (RSRQ), the referenced signal received power (RSRP) and the signal to interference plus noise ratio (SINR) were presented. Moreover, during data transfer, the authors investigated the impacts of signal to noise ratio (SNR) on the throughput performance. At this point, the experiment witnessed the occurrence of handover and further investigation was done based on how the handover was influenced by the four LTE measurements.

In [13], the researchers offered techniques to enhance the throughput of a live LTE network. The throughput was enhanced by modulating numerous parameters such as channel quality offset, power, interference and channel traffic load. They optimized these parameters, which led to enhance throughput of the LTE network.

In [6], a comparative analysis was conducted on 3G (UMTS) and 4G (Mobile WiMAX) mobile networks. At this point, the two mobile systems were evaluated through a simulator called QUALNET. After the measurements, the parameters were analyzed to get the average end-to-end delay, the Packet Delivery Ratio (PDR), collision and throughput. As compared to $3 \mathrm{G}$, the $4 \mathrm{G}$ resulted in higher PDR and throughput network. As per the research finding, $4 \mathrm{G}$ network possesses desirable quality of service (QoS) as compared to $3 \mathrm{G}$ mobile network.
In [14], a study was conducted based on a drive test within 2 $\mathrm{km}$ area for one cell coverage size. The study was performed based on various KPIs such as: the RSRP, SINR and throughput. The results show reported that there is a disturbance in all the performance of the three parameters, as the user equipment was moved towards the cell edges and away from the site area. The low power relay nodes can be deployed to address this issue, i.e., one of the encouraging methods to improve the coverage of LTE advanced networks besides advancing towards the latest technology, i.e., 5G networks.

Apart from these studies, literature contains many research studies that have determined the MBB performances of Second Generation (2G), 3G and 4G networks [15-24]. Researchers have performed these studies with the help of diverse systems under different environments. While these studies would have a significant impact on the MBB networks, these networks need to be further investigated keeping in vie the future planning. The rural and urban areas were mainly taken into account with respect to aforesaid studies. Until now, this level of research has not been conducted adequately for suburban areas.

Gaining an insight with the MBB performance and the actual experience of user in the suburban areas is the key objective of this study. Besides understanding the issues of the current MBB networks in the tested area, this helps consumers to identify the outperformance of $4 \mathrm{G}$ versus $3 \mathrm{G}$ technology. With this information, the relevant agencies will be enabled to make strategic plans to carry on or even upgrade the existing MBB services in Malaysia, particularly when the mobile traffics are likely to grow exponentially. The performance data from the three Malaysia MNOs' networks was collected through the research conducted on mobile broadband performance. The data collected between January and February has yielded in the presented outcomes.

For suburban morphology, four different states in Malaysia, namely: Klang Valley and Selangor, Johor Sarawak, and Sabah were taken into consideration to obtain measurements. Samsung smartphone Galaxy S6 was used for measurement purpose. The two different MBB services, namely: the video streaming services and the web browsing were included in the measurements. As far as the web services are concerned, the Google, Instagram and mStar were among the frequently browsed webpages. While, in the case of video streaming services, two videos were frequently watched that contained different resolutions, 1080p high and 720p low resolution video. The real communication scenarios were simulated, where the smartphones cannot be locked to any mobile technology. The coverage, satisfaction, latency and speed were the four KPIs, which were measured on behalf of the KPIs. Subsequent to the designed research set up, the $2 \mathrm{G}, 3 \mathrm{G}$ and $4 \mathrm{G}$ technologies were included in the MBB data being collected for every tested area.

On the basis of numerous KPIs, the $4 \mathrm{G}$ networks have reported greater performance than that of $3 \mathrm{G}$ networks as per the presented results. For example, for MBB video-streaming service, a vMOS score of above 3.3 was achieved by $4 \mathrm{G}$ networks, while $3 \mathrm{G}$ networks attained below 2.6 across all the four studied areas. Moreover, as compared to $3 \mathrm{G}$ technology, an improvement factor of up to 2.83 and 2.86 was revealed by 
the $4 \mathrm{G}$ technology in download speed, when a web page browsing and a video streaming were taken into account. Based on these study findings, the $5 \mathrm{G}$ networks can be planned efficiently in Malaysia, where the current $4 \mathrm{G}$ infrastructures will continue to support the $5 \mathrm{G}$ networks. The first step in the direction of the deployment of $5 \mathrm{G}$ mobile technology in Malaysia is to examine the $4 \mathrm{G}$ coverage performance.

Keeping the smartphones in view, the performance of $3 \mathrm{G}$ and $4 \mathrm{G}$ networks were focused in this research. Our research did not undertake the following factors: (i) mobile broadband services provided to other devices (such as dongles, MiFi devices and tablets); (ii) mobile messaging and mobile voice; (iii) careful study of public WiFi services. (Some mobile broadband tariffs were reportedly integrated with these $\mathrm{WiFi}$ services and can affect the quality of experience offered to a consumer), and (iv) Research team overlooked the $2 \mathrm{G}$ network, since the amount of data collected for $2 \mathrm{G}$ network was insignificant.

The rest of this paper is divided as follows: Section 2 describes the research limitations and future direction; Section 3 explains the methodology and system model; Section 4 and 5 explores the average performance of Web Browsing and Video Streaming respectively. The MBB performance is subsequently compared with different areas and then our testing results were discussed. At the end, the conclusion of this study will be given at Section 6.

\section{Methodology And System Model}

The researchers provided a detailed review of the performance of $4 \mathrm{G}$ vs $3 \mathrm{G}$ mobile networks. There is no comparable study that incorporates several suburban areas in Malaysia as per our knowledge. On the basis of drive tests, real measurements and scenarios, the research team has considered two diverse mobile applications with different KPIs. The performance of measured mobile networks is analyzed in this paper. Attributed to the different applications and various KPIs, this study aims to evaluate network performances. Hence, the development of $5 \mathrm{G}$ mobile networks will be enabled in Malaysia across suburban areas, especially the zones experiencing data speed rate and coverage latency issues. In addition, the operators will also be encouraged to enhance data rates, coverage and overall mobile network throughput across the area where reception is generally poor. Throughout the deployment of $5 \mathrm{G}$ mobile networks, the operators can successfully identify the regions that require further improvement.

For that, this section presents the research methodology used for collecting data and conducting this study. That entails the software and hardware employed, the test processes, the tested geographical areas, quality control characteristics, MBB services, and MNOs. As presented in our earlier works [25-27], the rural and urban areas of Malaysia have witnessed the implementation of this methodology. Nevertheless, the testing areas and the morphology type are totally different in this research. The team has witnessed the unique results, findings, discussions and concluding remarks.
The metrics pertaining to the user experience of using mobile broadband will be gauged by our test methodology. Owing to its careful configuration, it has the potential to generate a statistically robust dataset, which handles each MNO on neutral basis.

We have designed our test processes to make sure that every network was examined on an equal basis:

- Same handsets were employed for each network.

- Each network was tested in parallel to observe the uniform environmental conditions for each operator.

- Besides ensuring that simultaneous tests were not run on the similar network, undue debate was prevented by simultaneously testing the networks.

A proprietary software testing application was used for data acquisition, Speed video was employed for video streaming services and MBB explorer for web browsing services. Huawei Technology was our supplier. The selection of two software is based on the reasons given below:

- Modification of the handsets is not needed by the testing app itself.

- An app loaded on to the test device can determine and test the Speed video and MBB explorer apps, through which, the customized test sets become close to the consumer experience of mobile broadband use.

- As a result of the test apps, the test continues to run in cycle, which makes it convenient as less interaction is happened between the phones and the tester.

- In Thailand and Singapore, the web and video MBB user experiences have been determined through both the softwares. Compared with our bordering countries in South East Asia regions, we can thus make fair benchmarking on the user experience across Malaysia.

The MBB explorer app measures the following KPIs of web browsing services:

- Total Service Attempt (Count) and Average Page Display Success Ratio

- Cellular signal strength $(\mathrm{dBm})$

- Average Page Download Throughput (kbps)

- Average Page Response Latency (ms)

- Average of Ping RTT Delay (ms)

- Average Page Display Latency (ms)

The Speed video app measures the following KPIs of video streaming services:

- Cellular signal strength $(\mathrm{dBm})$

- Average Mobile vMOS Score (Scale 1 to 5 ; Worst = 1; Best $=5$ )

- Total Service Attempt (Count) and Average Initial Buffering Success Ratio

- Average Video Total Download Rate (kbps)

- Average Initial Buffering Latency (User perceived delay) (ms)

- Average Total Rebuffering Latency (ms)

- Average of Average Ping RTT Delay (ms)

\section{A. Our Test Process}

To experimentally evaluate the web-browsing MBB services, access to 3 different websites is required in each use cycle of the MBB explorer application: Google, Instagram and mStar 


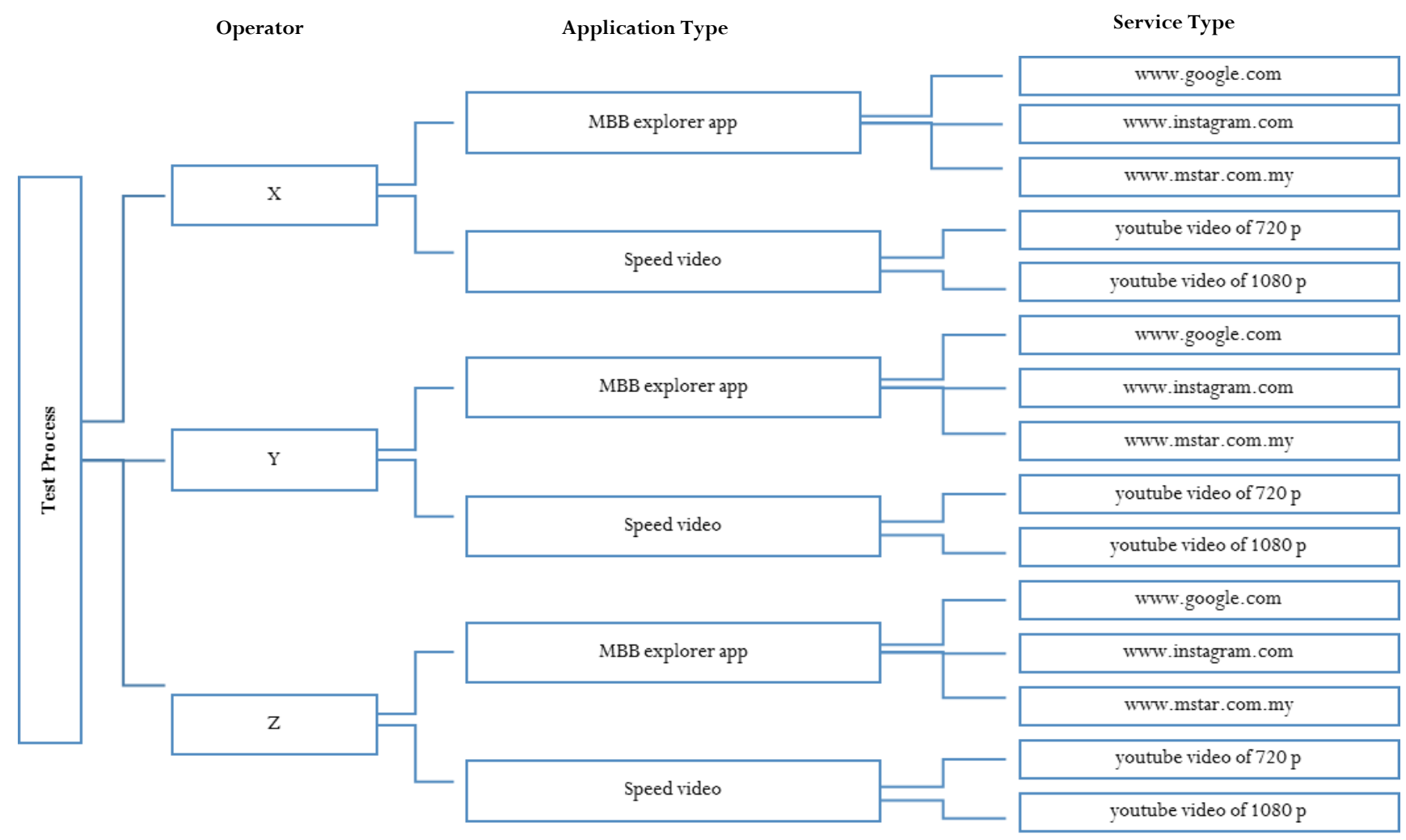

Fig.1. The main structure of test process with the considered MNOs, mobile applications, and service types used in the suburban Area

that are categorized as light, medium and heavy sized websites, respectively. The general testing structure for test process used is demonstrated in Figure 1. The reason for categorizing Google as light-sized is that just the homepage of the search engine is accessed by the testing application. Since Instagram is a photosharing website, it is classified as medium-sized. mStar is a famous news website in Malaysia and as it consists of texts, images and videos, it is considered as heavy-sized.

The testing of video-streaming services, which is performed by using the Speed video application, was carried out by including YouTube video streaming with high-resolution (1080p) and low-resolution (720p) in each testing cycle. The MBB explorer can be fixed at 100 testing cycles whereas Speed video can run for any number of cycles fixed by the user.

\section{B. Quality Control}

For additional processing, the MBB data gathered by the two mobile applications was automatically stored in a database. Also, A pre-test exercise including a 10-minutes' drive test was carried out to check whether the data obtained is stored properly or not. The time stamps were also used to check whether the previous MBB data measurements were successfully stored. It is ensured through this quality control exercise that there is no data loss or missed attempts while collecting MBB data.

\section{Test Types}

Measurements for outdoor environments were obtained. A drive test is carried out on the main roads of the specified towns and cities and across the inter-town main roads and various highways. The drive speed is fixed at below $60 \mathrm{~km} /$ hour for cities/towns and inter-towns federal road measurements, whereas it can be up to $80 \mathrm{~km} /$ hour for highway.

\section{MNO SIM Cards}

This research considers three MNOs. The three MNOs are classified as $\mathrm{X}, \mathrm{Y}$ and $\mathrm{Z}$ because the aim of the study is to understand the mobile user experience served by various MBB networks in Malaysia and not to create a benchmark for the performance of the MNO networks. For each MNO, the consumer prepaid sims were bought from its particular store to make sure that they represented the given consumer tariffs. Two SIMs were brought from each MNO as two kinds of tests would be carried out in the research

\section{E. Tested Areas}

The MBB tests were carried out in January and February in four Malaysian states, which are Klang Valley/Selangor, Johor, Sabah and Sarawak. These intensive measurements would be carried out in the given time periods by two teams of researchers. The first team would obtain measurements in the states of Johor and Klang Valley/Selangor and the second team would perform the test in Sarawak and Sabah. The suburban morphologies are examined using 14 drive test areas across the four states. The regions of the drive tests are shown in Table 1.

Figures 2 to 5 show the GPS route records we performed in the four considered places. The application of GPS Trip Recorder was installed on another mobile phone that was used only to obtain the GPS route record. The GPS route was recorded by the phone with the GPS Trip Recorder, while the MBB test parameters were measured with the Samsung Galaxy 6 phone. 
TABLE 1. Morphologies Areas: Tested Areas in the Suburban Morphologies

\begin{tabular}{|c|c|c|c|c|}
\hline Morphologies & $\begin{array}{c}\text { Klang Valley (KV) and } \\
\text { Selangor }\end{array}$ & Johor & Sabah & Sarawak \\
\hline Suburban & $\begin{array}{l}\text { 1. Kajang and Hulu } \\
\text { Langat; } \\
\text { 2. Rawang }\end{array}$ & $\begin{array}{ll}\text { 1. } & \text { Segamat; } \\
\text { 2. } & \text { Muar; } \\
\text { 3. } & \text { Kluang; } \\
\text { 4. } & \text { Batu Pahat }\end{array}$ & $\begin{array}{l}\text { 1. Keningau; } \\
\text { 2. Ranau; } \\
\text { 3. Kudat; } \\
\text { 4. Sandakan; } \\
\text { 5. Lahad Datu; } \\
\text { 6. Tawau }\end{array}$ & $\begin{array}{l}\text { 1. Bintulu; } \\
\text { 2. Sibu }\end{array}$ \\
\hline
\end{tabular}

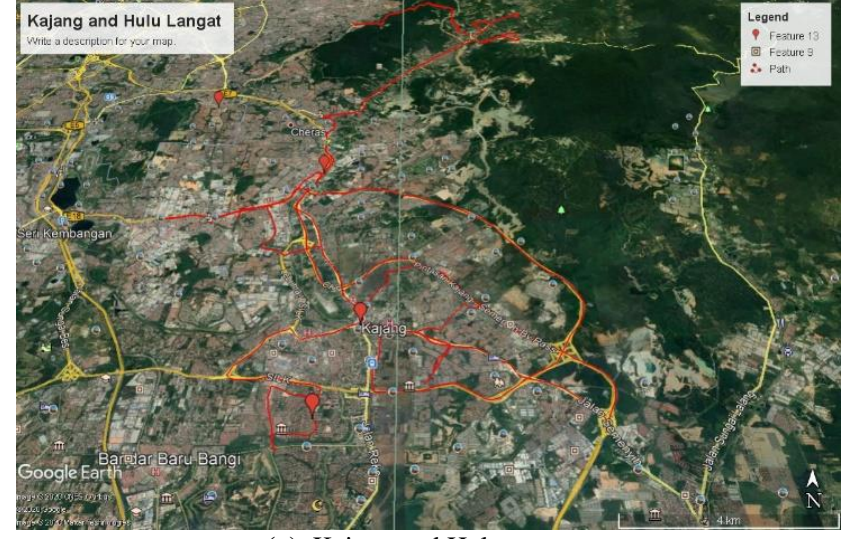

(a) Kajang and Hulu

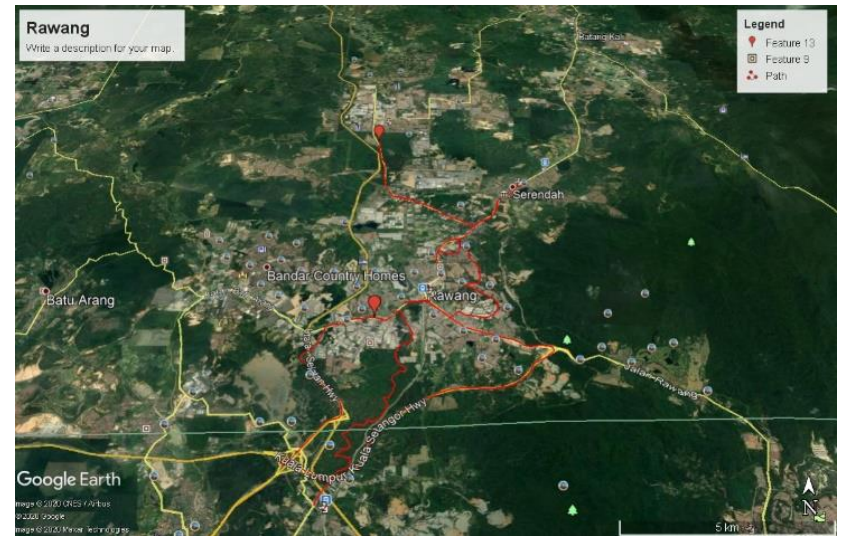

(b) Langat; Rawang

Fig.2. GPS Route Measurements Record in Suburban of Klang Valley State, Malaysia

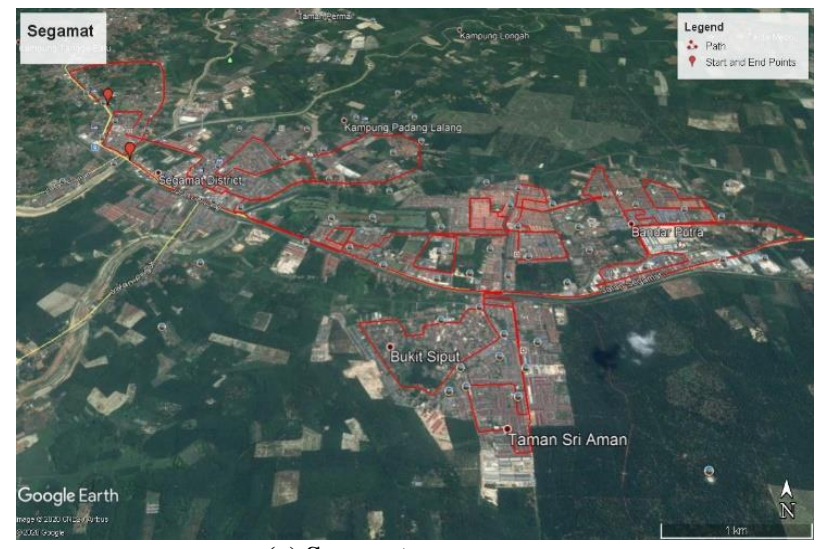

(a) Segamat

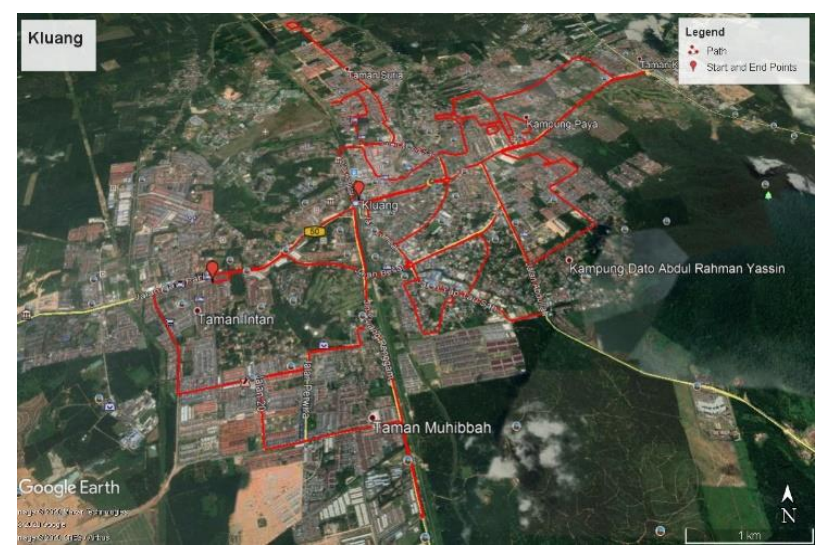

(c) Kluang

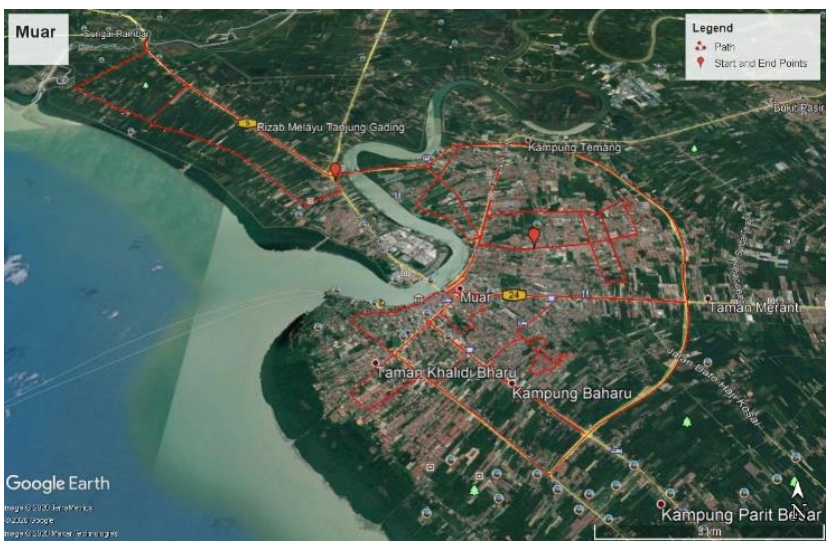

(b) Muar

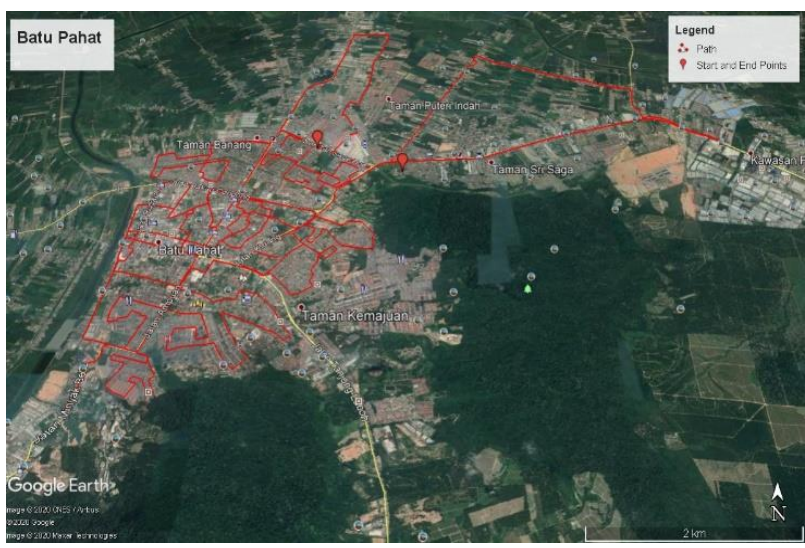

(d) Batu Pahat

Fig.3. GPS Route Measurements Record in Suburban of Johor Bahru State, Malaysia 


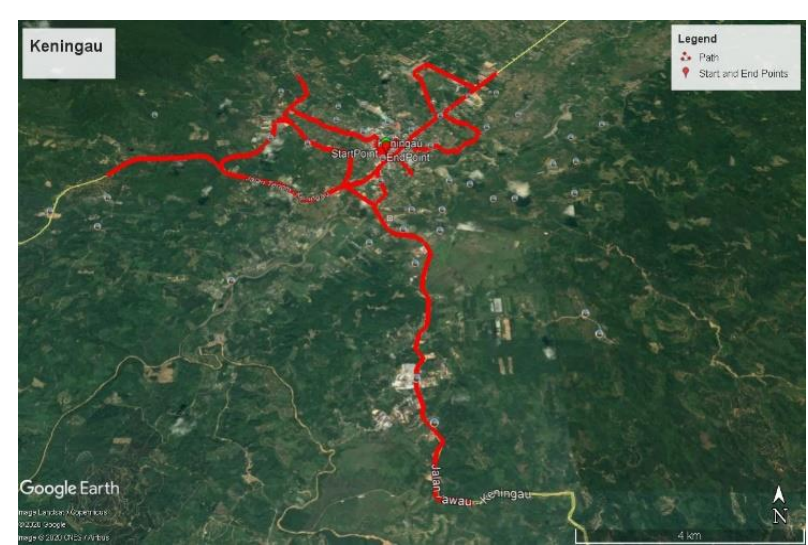

(a) Keningau

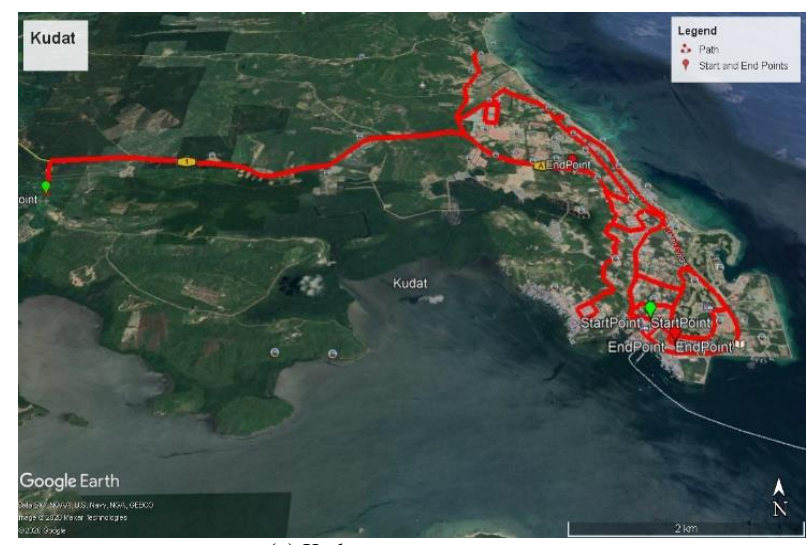

(a) Kudat

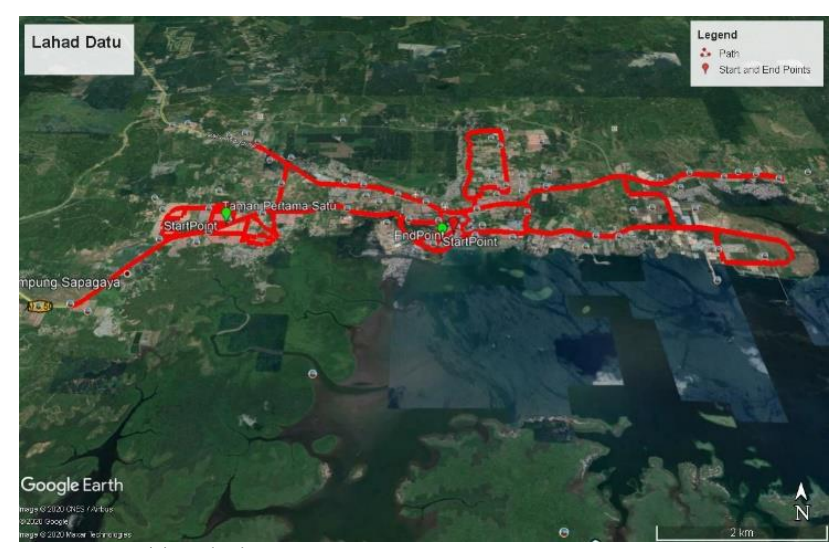

(a) Lahad Datu

Fig.4. GPS Route Measurements Record in Suburban of Sabah Kota Kinabalu Areas.

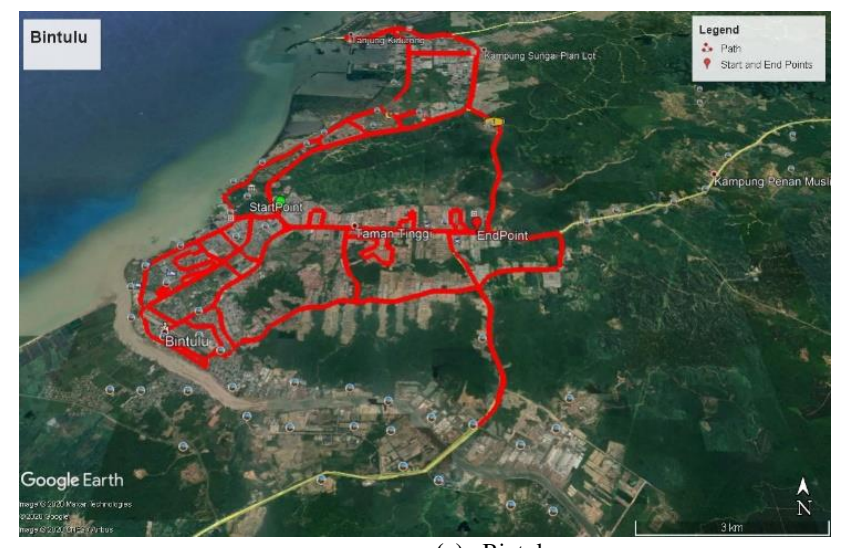

(a) Bintulu

Fig.5. GPS Route Measurements Record in Suburban of Sarawak State, Malaysia

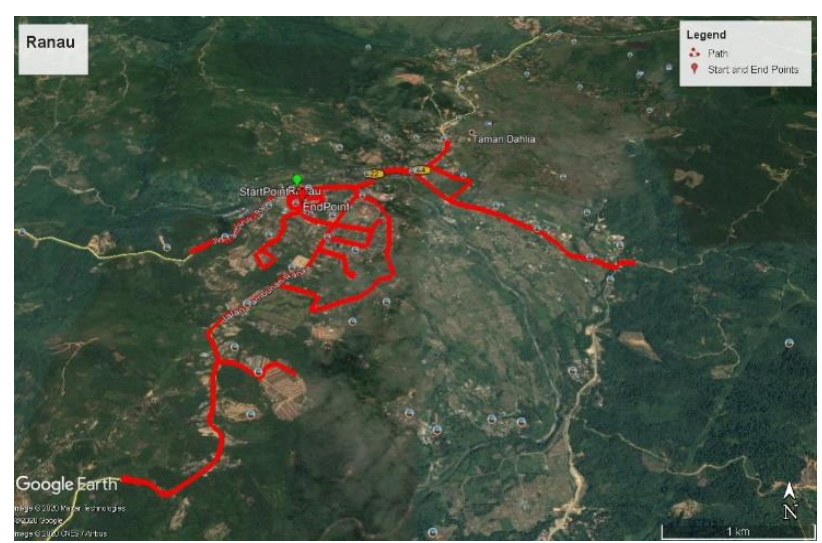

(b) Ranau

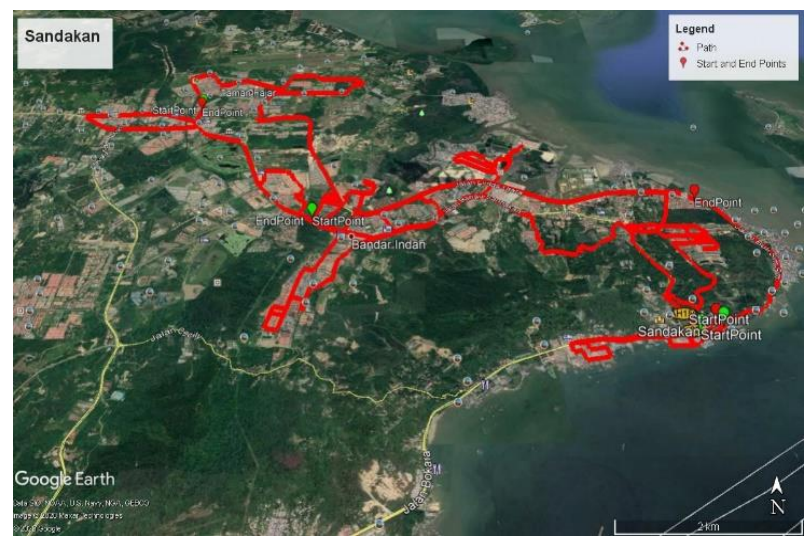

(b) Sandakan

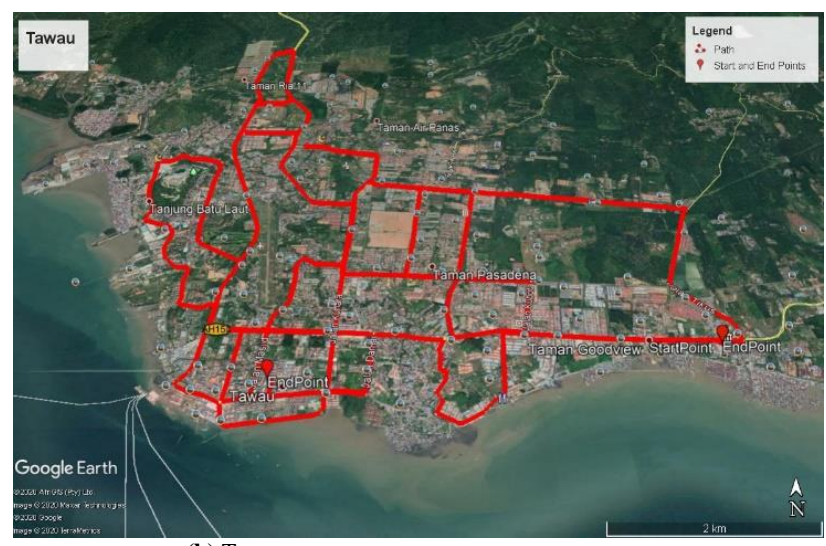

(b) Tawau

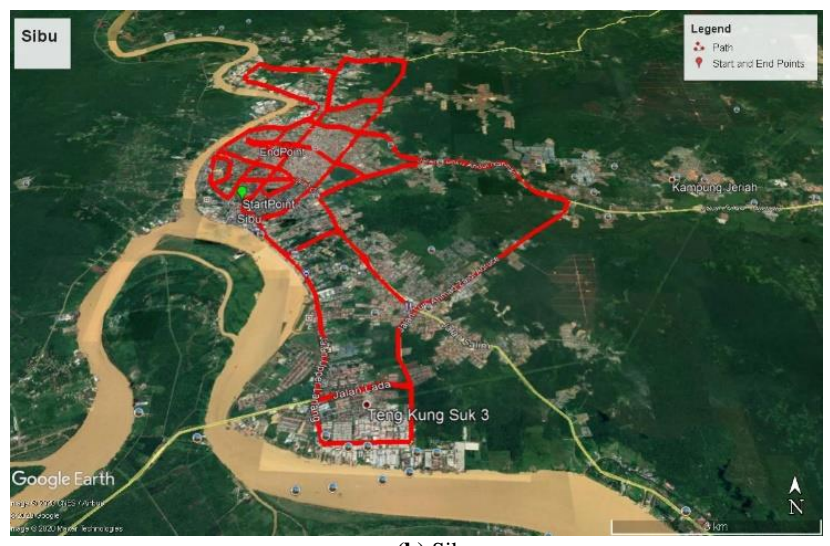

(b) Sibu 


\section{PERFormance OF Web Browsing}

The findings show the network performance for the periods in which the tests were carried out and for the areas from which we obtained the measurements. Each network was tested at the same time at every testing location to make sure that the comparison between the three MNOs was impartial. All the smartphones used were generic and unaltered, with the same specifications, build and the operating system. It was also ensured that no bias was introduced into the outcomes due to this. Either $3 \mathrm{G}$ or $4 \mathrm{G}$ technologies are used to access the data gathered from the Samsung Galaxy smartphones in suburban morphologies. No data is collected using $2 \mathrm{G}$ technology.

In this section, only the findings obtained from the WEB Browsing application are presented and discussed. In the subsections, various KPIs are used, and these will be elaborated. The overall findings from KPIs of web browsing services are discussed in the subsequent subsections, including: (1) cellular signal strength; (2) total service attempt (count) and average page display success ratio; (3) average page response latency; (4) average page download throughput; (5) average of ping RTT delay and (6) average page display latency.

\section{A. Network Signal Coverage}

The measured cellular signal strength represents the mobile network signal coverage. Figures 6 and 7 show the distributions of cellular signal strength for $4 \mathrm{G}$ and $3 \mathrm{G}$ mobile networks, respectively. In these figures, the $\mathrm{Y}$-axis represent the number of web access cycles, while the $\mathrm{X}$-axis represents the cellular signal strength of web services. The number of web access cycles refers to the number of cycles that the Google, Instagram and $\mathrm{mStar}$ pages are accessed by the MBB explorer application. One web access cycle represents browsing one of these pages.

Results in Figure 6 show that, the received signal power of $4 \mathrm{G}$ mobile networks is ranging between $-120 \mathrm{dBm}$ and -50 $\mathrm{dBm}$ for all the four states. Majority of the recorded signal power is, however, between the range of $-105 \mathrm{dBm}$ and -75 $\mathrm{dBm}$. In contrast, the results in Figure 7 show that the received signal power of $3 \mathrm{G}$ mobile networks is ranging between -110 $\mathrm{dBM}$ and $-55 \mathrm{dBm}$ in the four states. Majority of these recorded signal power is between the range of $-110 \mathrm{dBm}$ and $-70 \mathrm{dBm}$. Moreover, the results show that the number of recorded access cycles for the $4 \mathrm{G}$ networks is greater than the accesses to $3 \mathrm{G}$ mobile networks. This may happen due to two different reasons. First, better coverage is provided by $4 \mathrm{G}$ compared to that of $3 \mathrm{G}$ mobile networks. Secondly, more resources are provided by $4 \mathrm{G}$ in comparison to the $3 \mathrm{G}$ mobile networks in the measured four states.

Table 1 shows a statistical comparison between the two mobile technologies in the four states. It can be seen in the table that $80 \%$ coverage in the tested region is stronger compared to the given web cellular signal strength. Separate findings are given for each operator. According to the given results, better performance is shown by a few operators compared to others; however, these differences are only minor. It can be deduced from these findings that better coverage is offered by the $4 \mathrm{G}$ networks in comparison to the $3 \mathrm{G}$ networks for all the suburban regions. In addition, in the given suburban area, more $4 \mathrm{G}$ networks are deployed compared to the $3 \mathrm{G}$ networks, suggesting that $4 \mathrm{G}$ was the dominant network in these regions.

\section{B. Network Satisfaction}

This subsection discusses the overall number of web access attempts and the overall page display success ratio for browsing websites services. The total counted number of cycles signifies the total web access attempts. Getting the highest total number of web access attempts means that serving network provide good mobile connection. The overall page display success ratio is the ratio of the overall number of pages displayed successfully to the overall number of mobile web access attempts. It is not necessary for the overall web access attempts to be the same for both the $3 \mathrm{G}$ and $4 \mathrm{G}$ networks. Slightly, it relies on the network availability and to which the mobile is connected.

Figure 8 show the total attempts made to access web services through the drive test experiments. According to the findings, to access the internet for web services, 4G technologies are predominantly used, with $90.4 \%, 84.7 \%, 78.5 \%$ and $89.9 \%$ for Klang Valley, Johor, Sabah and Sarawak, respectively. It is also confirmed in Figure 9 that out of the three web pages, the best performance is noted for Google for all places using the $4 \mathrm{G}$ mobile technology. The performance of $3 \mathrm{G}$ networks all over Malaysia is clearly inadequate for accessing web pages at the given suburban regions.

\section{Network Download Speed}

In this subsection, the network download speed of web services for suburban areas in the four tested states is discussed. Achieving the maximum download speed suggests that good mobile speed is being provided by the network for the given serving network at that particular tested region. The network download speed offered by $4 \mathrm{G}$ networks should theoretically be more than what the $3 \mathrm{G}$ network can offer. However, if the network download speed offered by the $4 \mathrm{G}$ networks is less than that offered by $3 \mathrm{G}$ networks, it may be because $4 \mathrm{G}$ technology is not widely available in that particular region.

Figure 10 presents the experimental findings of the average page download throughputs of web services for all states, MNOs and networks. The findings show that the highest web browsing speed using $4 \mathrm{G}$ is provided by the state of Sabah. On the whole, an improvement of 3.8, 2.2, 1.5 and 1.6 times is observed in the $4 \mathrm{G}$ web download speed compared to the $3 \mathrm{G}$ web download speed in Klang Valley, Johor, Sabah and Sarawak, respectively.

According to these findings, the actual download speed is less than the theoretical LTE download speed. The actual download speed reaches a maximum of $6.02 \mathrm{Mbps}$, whereas the highest LTE speed that can be theoretically obtained by mobile users is $100 \mathrm{Mbps}$. The key factor for achieving this practical speed is the overall cell load traffic. When the number of users in the cell increase, the number of resources in the cell will decrease linearly.

The findings of the overall page display success ratios for every 3G/4G technology and MNO are depicted in Figure 9. The page display success ratio refers to the proportion of successful display of web pages from the total number of attempts made to access the web pages. The success scenario is demonstrated by the two figures, while also clearly showing the proportion of failed attempts. The failed attempts ratio is a lower ratio compared to the success ratio. For example, when the success ratio is $0.98 \%$ and the failed attempts ratio is $0.02 \%$, 

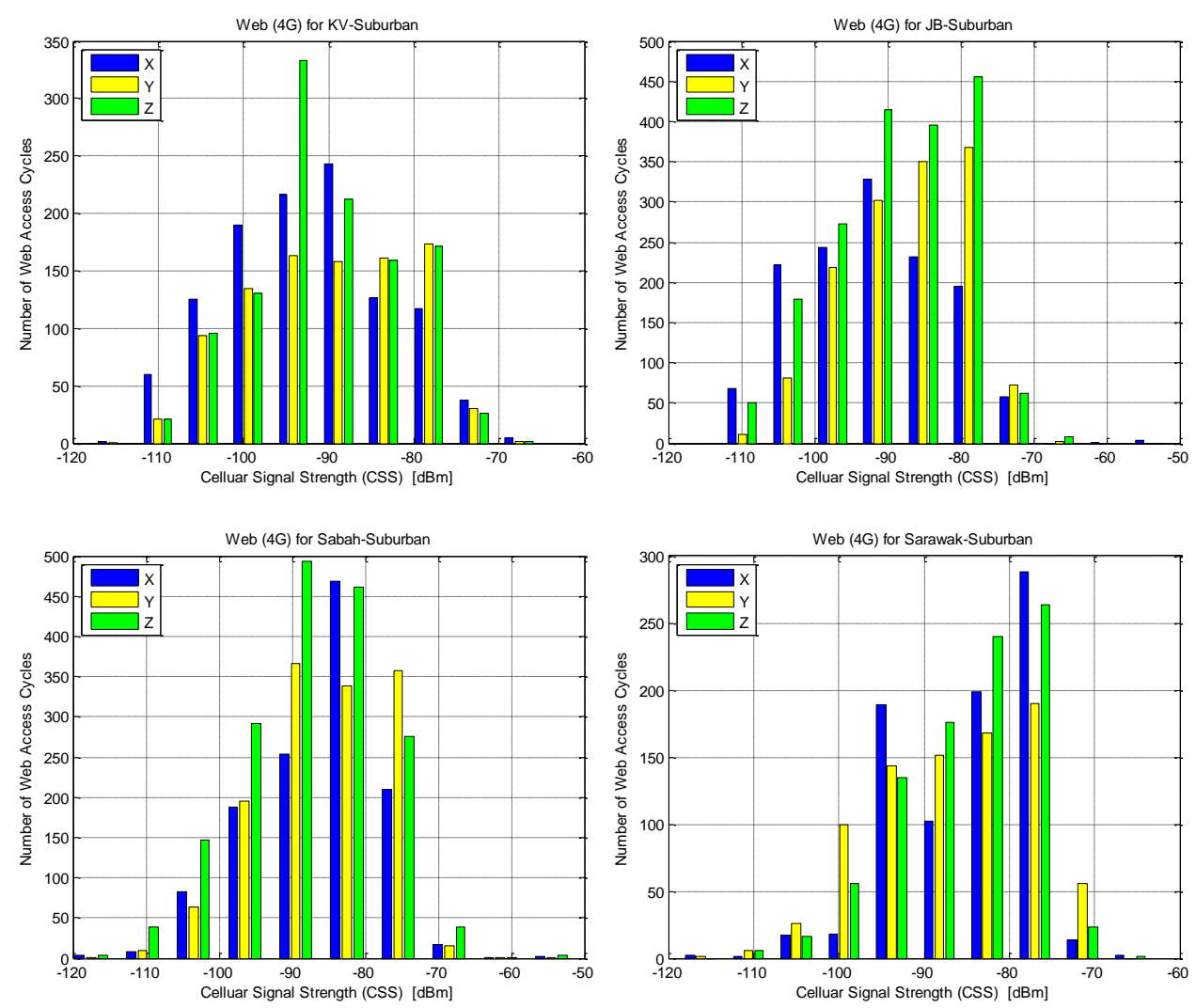

$\mathrm{PDF}$ of the received cellular signal strength of $4 \mathrm{G}$ mobile technology for web browsing measured at four suburban morphologies
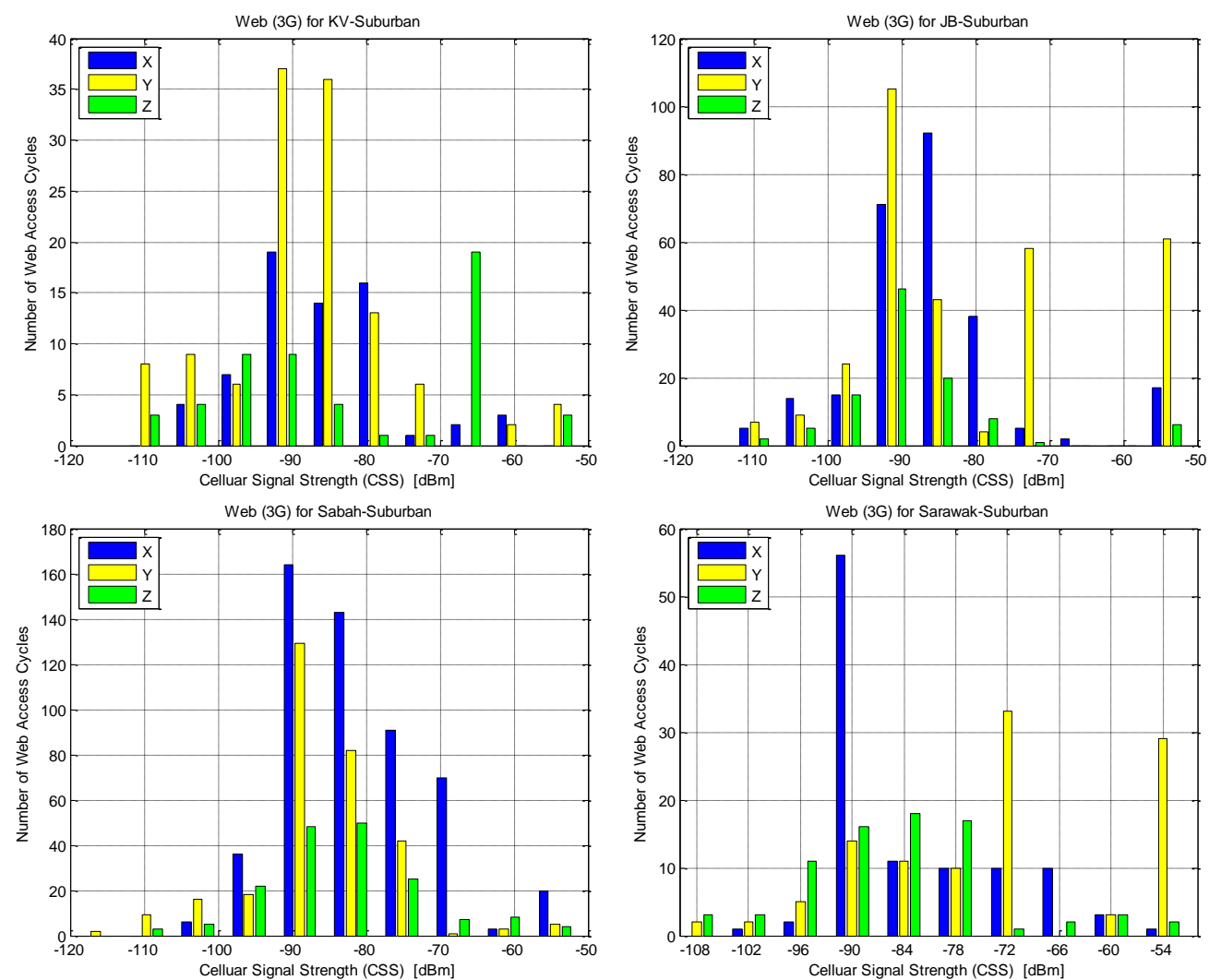

Fig.7. PDF of the received cellular signal strength of $3 \mathrm{G}$ mobile technology for web browsing measured at four different suburban morphologies 
The $80 \%$ of the measured coverage in the tested suburban morphologies is stronger than the given web cellular signal strength stated in this table.

\begin{tabular}{|c|c|c|c|c|c|}
\hline \multirow{2}{*}{ MNO } & \multirow{2}{*}{ NETWORK TYPE } & \multicolumn{4}{|c|}{ AREA } \\
\hline & & KLANG VALLEY & JOHOR & SABAH & SARAWAK \\
\hline \multirow{2}{*}{$\mathrm{X}$} & $4 \mathrm{G}$ & $-101 \mathrm{dBm}$ & $-101 \mathrm{dBm}$ & $-93 \mathrm{dBm}$ & $-91 \mathrm{dBm}$ \\
\hline & $3 \mathrm{G}$ & $-91.6 \mathrm{dBm}$ & $-91 \mathrm{dBm}$ & $-89 \mathrm{dBm}$ & $-90.4 \mathrm{dBm}$ \\
\hline \multirow{2}{*}{$\mathrm{Y}$} & $4 \mathrm{G}$ & $-99 \mathrm{dBm}$ & $-95 \mathrm{dBm}$ & $-92 \mathrm{dBm}$ & $-95 \mathrm{dBm}$ \\
\hline & $3 \mathrm{G}$ & $-93 \mathrm{dBm}$ & $-91 \mathrm{dBm}$ & $-91 \mathrm{dBm}$ & $-87 \mathrm{dBm}$ \\
\hline \multirow{2}{*}{$\mathrm{Z}$} & $4 \mathrm{G}$ & $-97 \mathrm{dBm}$ & $-96 \mathrm{dBm}$ & $-95 \mathrm{dBm}$ & $-91 \mathrm{dBm}$ \\
\hline & $3 \mathrm{G}$ & $-97 \mathrm{dBm}$ & $-95 \mathrm{dBm}$ & $-91 \mathrm{dBm}$ & $-93 \mathrm{dBm}$ \\
\hline
\end{tabular}

it shows that there is satisfactory Quality of Service (QoS) of the network. According to the experimental findings, for the kinds of MNO reviewed in the study, 4G exhibits better network performance compared to $3 \mathrm{G}$. This result was expected because $4 \mathrm{G}$ technology has distinct features with respect to throughput and technology, as depicted in the subsequent subsections.

\section{Network Latency}

The outcomes for three kinds of network latencies are presented in this section, which are the web page response latency, web page display latency and web page ping average RTT. The three types of networks latencies are explained subsequently and shown in Figures 6, 7 and 8, respectively.

The average web page response latency for suburban morphology situated in four distinct states of Malaysia is depicted in Figure 11. Compared to 3G networks, 4G networks were found to have lower page response. In all of the tested states, the average latency of $4 \mathrm{G}$ networks on all the networks tested were $576.4 \mathrm{~ms}, 731.6 \mathrm{~ms}, 1008.5 \mathrm{~ms}$, and $818.0 \mathrm{~ms}$. On the contrary, the latency for $3 \mathrm{G}$ networks were found to be $2717.4 \mathrm{~ms}, 1689.1 \mathrm{~ms}, 1599.2 \mathrm{~ms}$ and $1543.0 \mathrm{~ms}$ for Klang Valley, Johor, Sabah and Sarawak, respectively. It is evident from this figure that lower latency is offered by the $4 \mathrm{G}$ networks compared to the $3 \mathrm{G}$ networks in the areas being tested.

The average web page display latency of all $3 \mathrm{G}$ and $4 \mathrm{G}$ operators in the testing regions is presented in Figure 12. It can be seen that there was lower average page display latency in suburban $4 \mathrm{G}$ networks compared to $3 \mathrm{G}$ networks. On the contrary, the lowest latency of $6305 \mathrm{~ms}$ is found for the $3 \mathrm{G}$ network in Johor for network operator Z. An average latency on the $4 \mathrm{G}$ network for all the networks tested in the test states was found to be $4860.8 \mathrm{~ms}, 5793.2 \mathrm{~ms}, 6098.7 \mathrm{~ms}$, and $7946.6 \mathrm{~ms}$. On the other hand, for the $3 \mathrm{G}$ network, it was found to be $6722.9 \mathrm{~ms}, 6853.8 \mathrm{~ms}, 7052.8 \mathrm{~ms}$ and $17357.7 \mathrm{~ms}$ for Klang Valley, Johor, Sabah and Sarawak, respectively.

The average ping average RTT latency for the testing areas is shown in Figure 13. This figure shows the delay of a 2-way journey of a packet from the source to the destination. This performance measure determines the latency on the basis of a ping. The ping average RTT latency for $4 \mathrm{G}$ networks was generally less compared to the $3 \mathrm{G}$ networks. The average of all networks tested across the test states showed latency on $4 \mathrm{G}$ to be $6.5 \mathrm{~ms}, 63.2 \mathrm{~ms}, 96.5 \mathrm{~ms}$, and $86.6 \mathrm{~ms}$ and on 3G to be 9.4 $\mathrm{ms}, 95.9 \mathrm{~ms}, 120.1 \mathrm{~ms}$ and $118.0 \mathrm{~ms}$ for Klang Valley, Johor,
Sabah and Sarawak, respectively. The average latency of the page response, page display and RTT for all the $4 \mathrm{G}$ operations is found to be nearly at the same levels for every testing area in contrast to the rest in $3 \mathrm{G}$. The reason for this is that all operators in this region have similar $4 \mathrm{G}$ network infrastructures because of which there is low latency of page response. Better performance and consistency is shown by the $4 \mathrm{G}$ networks in all testing regions in contrast to $3 \mathrm{G}$ networks.

The average latency levels of the page response, RTT and page display for all $4 \mathrm{G}$ levels is almost the same for every testing area in comparison to those of $3 \mathrm{G}$ network. This is a valid finding because the operators in these regions all have similar 4G infrastructures, due to which there is low latency for page responses. As compared to $3 \mathrm{G}$, the $4 \mathrm{G}$ networks offer better and consistent performance in all of the tested regions.

\section{E. WEB Results Summary}

Web service findings for the suburban morphology is concisely summarized in Table 3. The results are categorized in accordance with the different MNOs. The first, second and third sub-tables present findings for three distinct operators, $\mathrm{X}, \mathrm{Y}$ and $\mathrm{Z}$, respectively. The results for six distinct KPIs in four different states are given in each sub-table. A clear comparison between $3 \mathrm{G}$ and $4 \mathrm{G}$ network is presented in the table. Also, $\boldsymbol{A}$ vertical comparison between the measurement findings has first been performed across different operators for the same KPIs, state and technology, which are highlighted as red and blue boxes.

As horizontal comparison of the measurement findings is presented across the four states for the same operators, technology and KPIs, where the table legend includes blue box and red box colors.

According to Operator $\boldsymbol{X}$ performance, for $4 \mathrm{G}$ technology, the operator $X$ offered the best performance in $\mathrm{KV}$ state much better than the other all states. But for $3 G$ technology, the Operator $\mathrm{X}$ offered the best performance in KV and Sabah states better than the other states.

According to Operator $\boldsymbol{Y}$ performance, for $4 \mathrm{G}$ technology, the operator $\mathrm{Y}$ offered the best performance in $\mathrm{KV}$ state much better than the other all states. But for $3 G$ technology, the Operator $\mathrm{Y}$ offered the best performance in JOHOR and SARAWAK states better than the other states. 

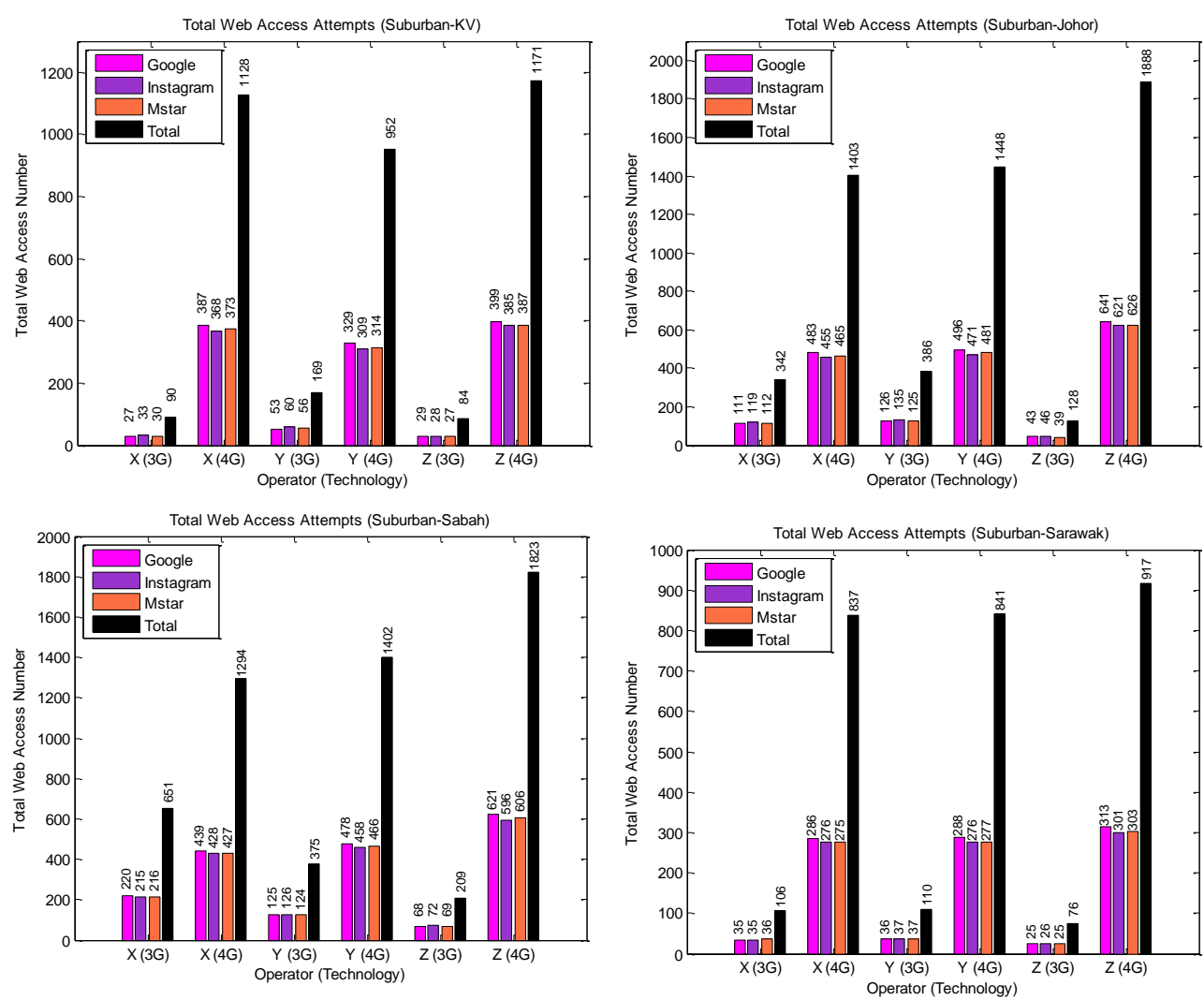

Fig.8. The total web access attempt measured at four different suburban morphologies and classified based on mobile technologies, MNOs and morphologies.
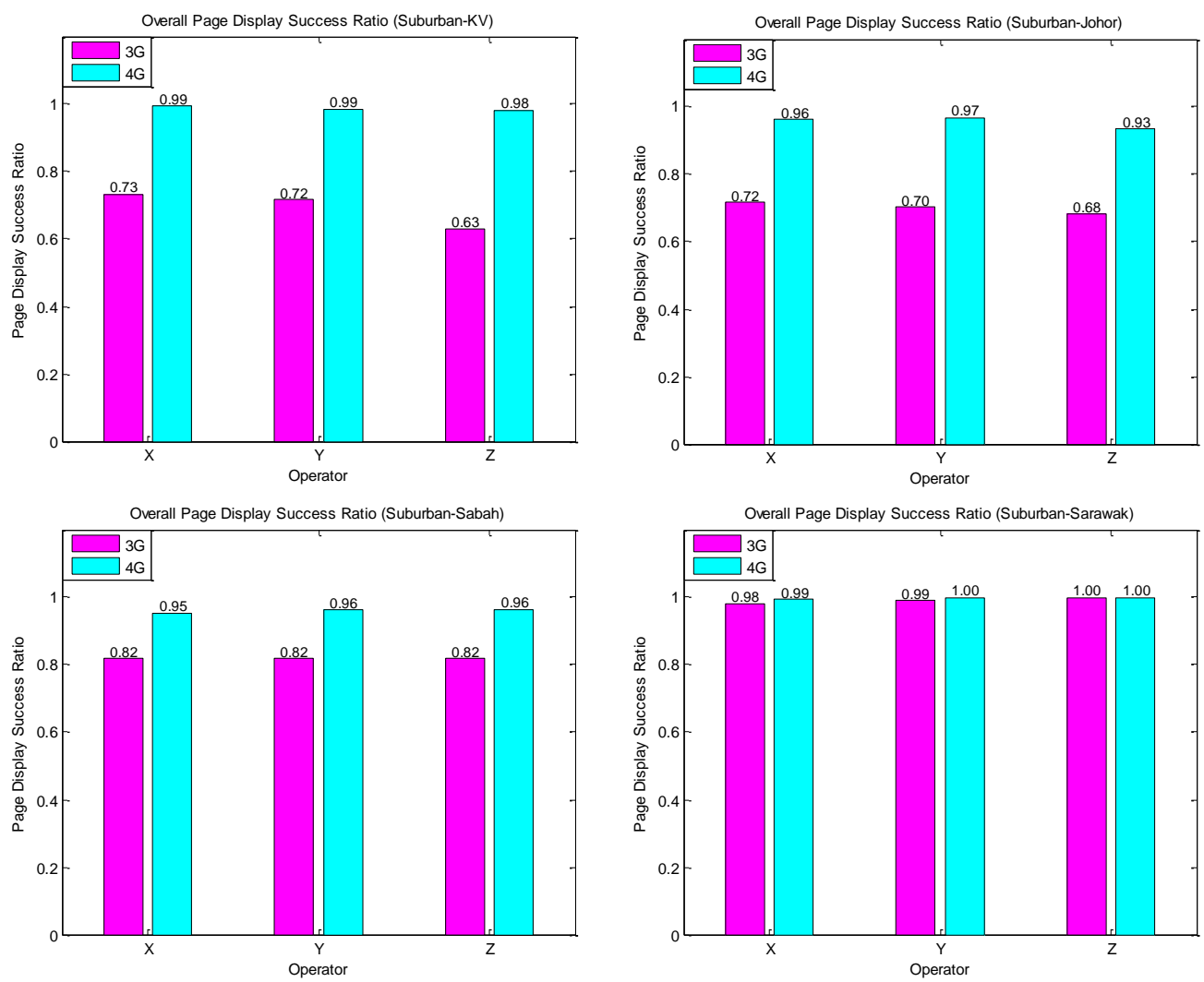

Fig.9. The overall page display success ratio measured at four different suburban morphologies located in four different states 

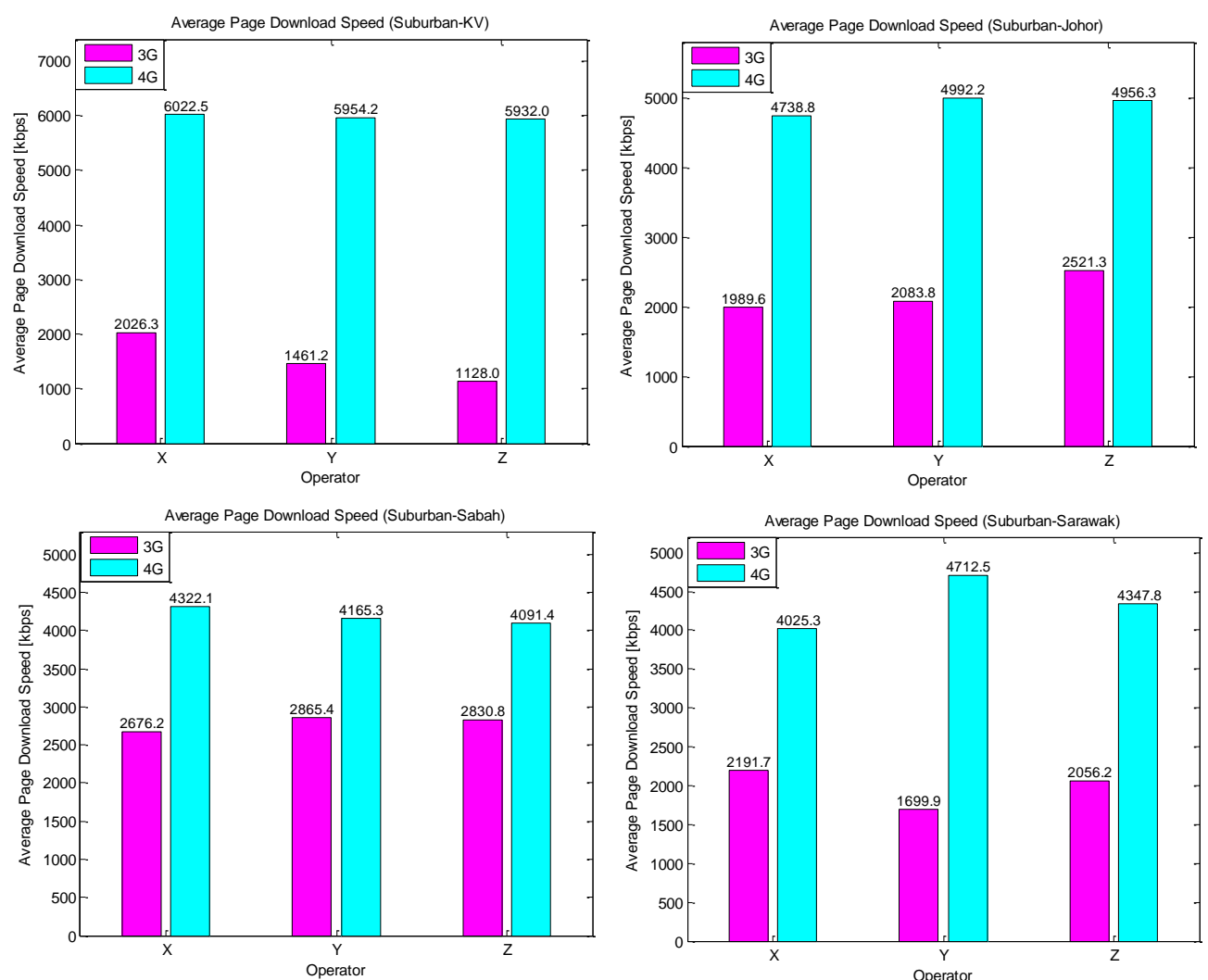

Fig.10. The average page download speed measured at four different suburban morphologies located in four different states, and categorized based on technologies
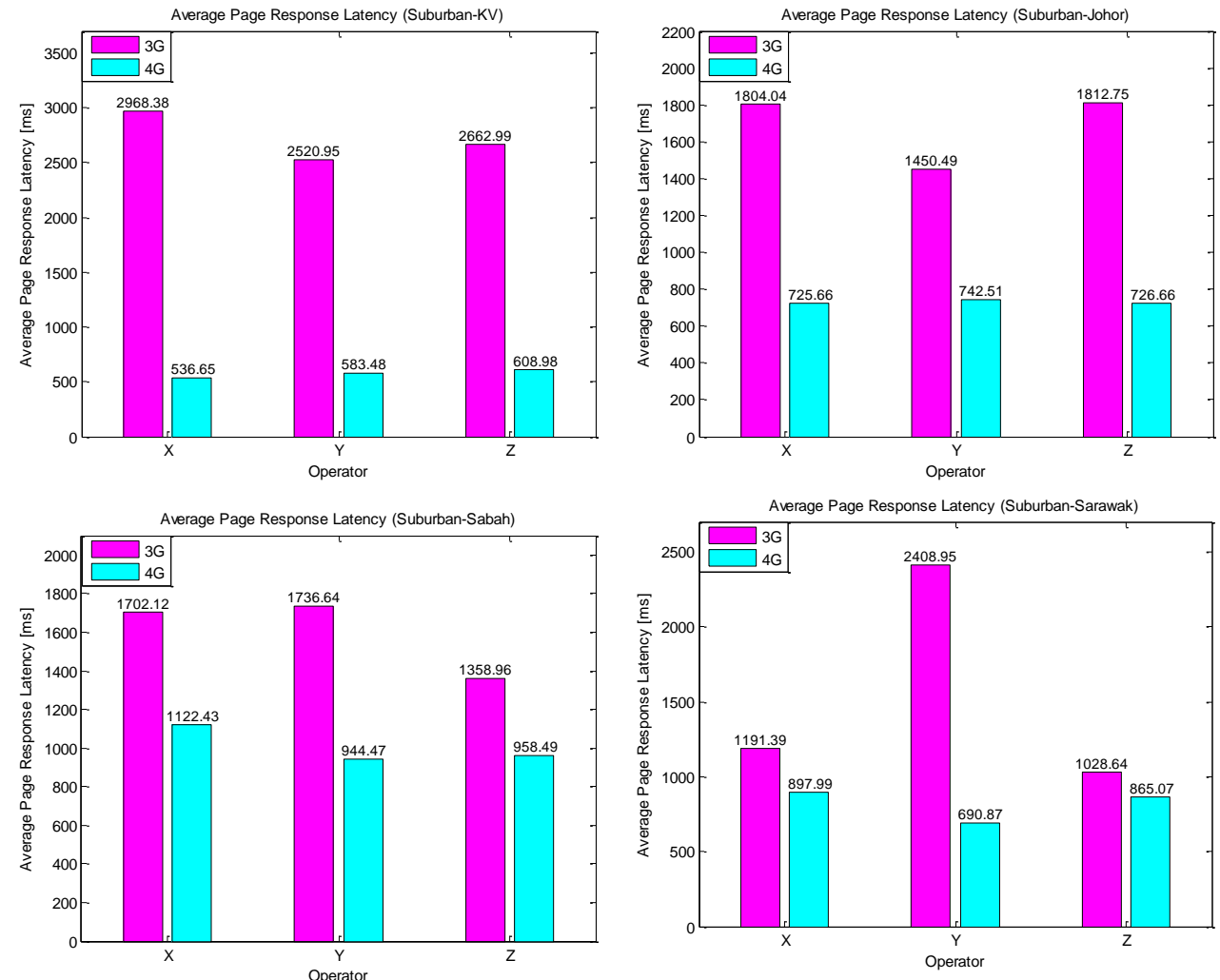

Fig.11. The average of web page response latency measured at four different suburban morphologies located in four different states, and categorized based on technologies 

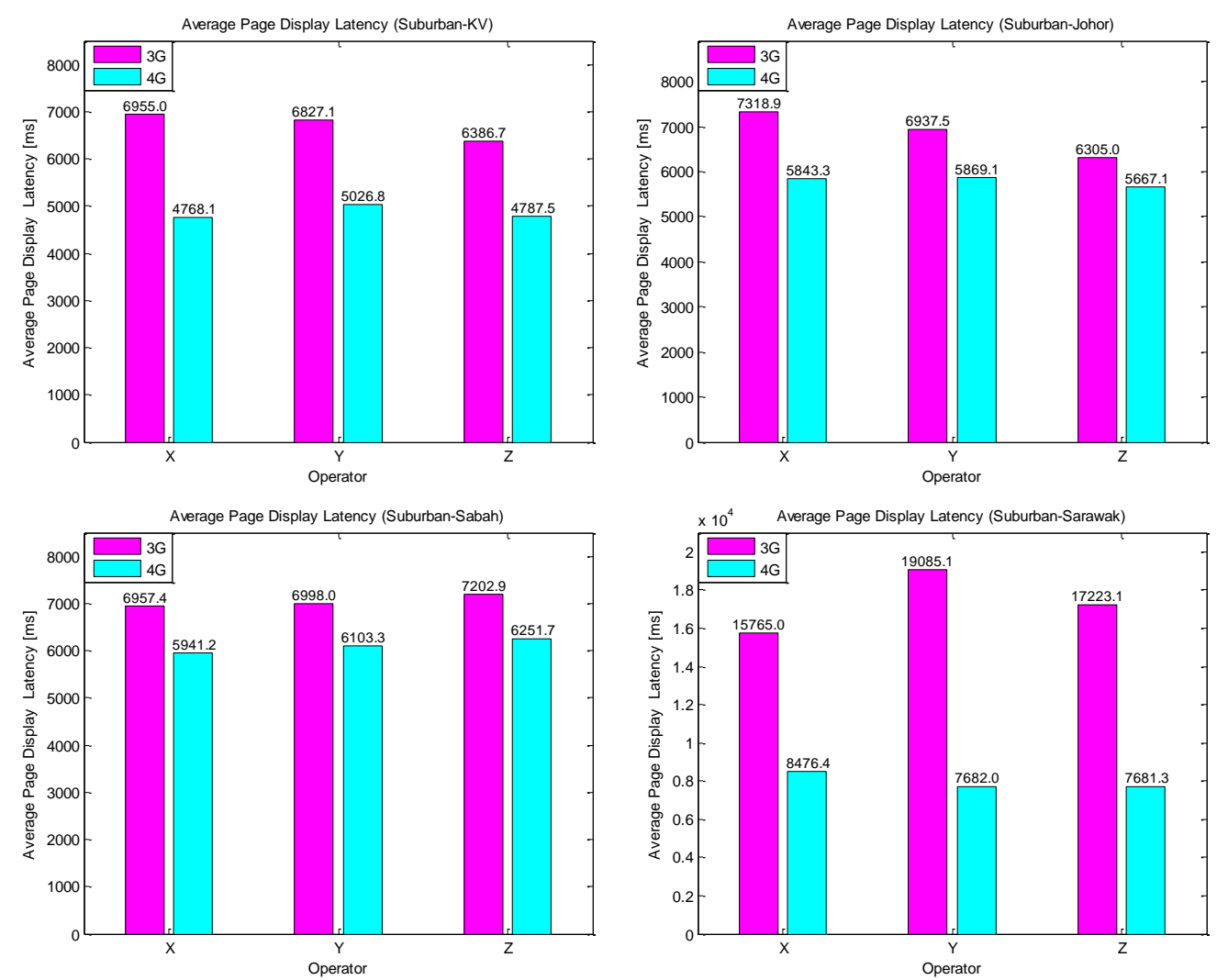

Fig.12. The average of web page display latency measured at four different suburban morphologies located in four different states, and categorized based on technologies
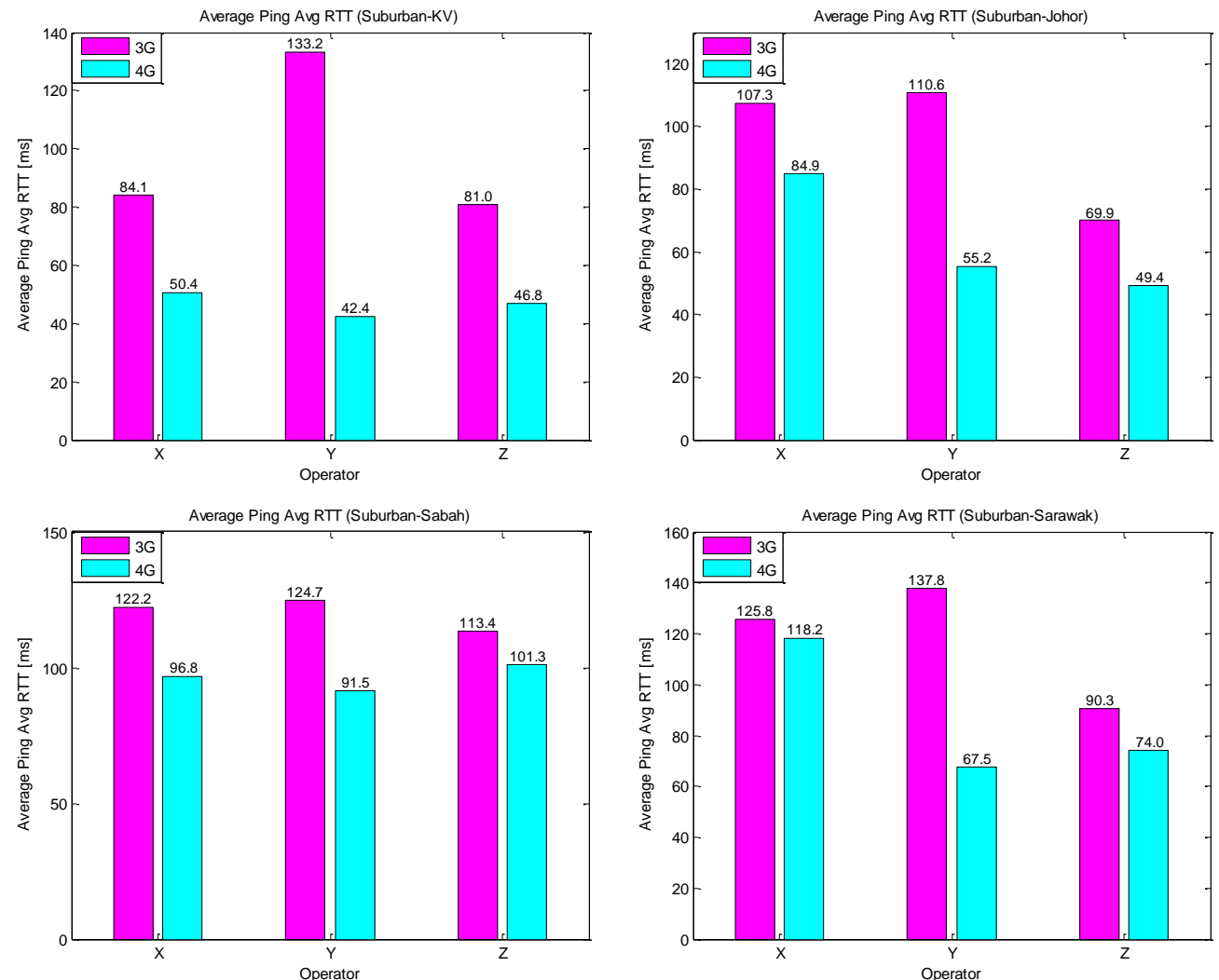

Fig.13. The average of web ping average RTT measured at four different suburban morphologies located in four different states, and categorized based on technologies 
According to Operator $Z$ performance, for $4 \mathrm{G}$ technology, the operator $\mathrm{Z}$ offered the best performance in $\mathrm{KV}$ state much better than the other all states. But for $3 G$ technology, the Operator Z offered the best performance in JOHOR and SARAWAK states better than the other states.

A vertical comparison, a comparison between the operators for the both technologies are performed. It can be seen that for $4 \mathrm{G}$ technology operator $\mathrm{X}$ offered better overall performance compared to $\mathrm{Y}$ and $\mathrm{Z}$ operators, with respect to web services overall states. That has been indicated by green circle around the highest values over all operators. Low $4 \mathrm{G}$ performance is exhibited overall by operator $\mathrm{Z}$ as compared to operators $\mathrm{X}$ and $Y$. On the contrary, it can be also seen that for $3 G$ technology operator $\mathrm{Z}$ offered better overall performance compared to $\mathrm{X}$ and $\mathrm{Y}$ operators, with respect to web services overall states.
That has been indicated by pink circle around the highest values over all operators. Low $3 \mathrm{G}$ performance is exhibited overall by operator $\mathrm{X}$ as compared to operators $\mathrm{Y}$ and $\mathrm{Z}$.

In general, $4 \mathrm{G}$ network have been seen to outperform $3 \mathrm{G}$ network with respect to every KPI, as illustrated in the table. However, the KPI of average cellular signal strength did not show the outperformance of $3 \mathrm{G}$ by $4 \mathrm{G}$ network. Hence, signal strength for web services in $4 \mathrm{G}$ network may be improved by expanding the expanse of $4 \mathrm{G}$ networks coverage areas. Moreover, each of the three service providers was found to depict competitive performance with reference to each KPI in each state.

In short, the outcomes tabulated in sub-tables highlight the outperformance of $3 \mathrm{G}$ networks in all testing areas by $4 \mathrm{G}$ network.

Fig.14.

Summary of web services for four different suburban morphologies and three different MNOs.

\begin{tabular}{|c|c|c|c|c|c|c|c|c|}
\hline \multirow[t]{3}{*}{ Morphology: Suburban } & \multicolumn{4}{|c|}{ Operator: X } & \multicolumn{4}{|c|}{ MBB service: WEB } \\
\hline & \multicolumn{2}{|c|}{ KV } & \multicolumn{2}{|c|}{ JOHOR } & \multicolumn{2}{|c|}{ SABAH } & \multicolumn{2}{|c|}{ SARAWAK } \\
\hline & $3 G$ & 4G & $3 G$ & 4G & $3 G$ & 4G & $3 G$ & $4 G$ \\
\hline $\begin{array}{r}\text { Overall Page Display Success Ratio } \\
\text { [Higher is better] }\end{array}$ & 0.73 & 0.99 & 0.72 & 0.96 & 0.82 & 0.95 & 0.98 & 0.99 \\
\hline $\begin{array}{r}\text { Average Page Response Latency (ms) } \\
{[\text { Lower is better] }}\end{array}$ & 2968.4 & & & 725.7 & 1702.1 & 1122.4 & 1191.4 & 898.0 \\
\hline $\begin{array}{c}\text { Average Page Display Latency (ms) } \\
\text { [Lower is better] }\end{array}$ & 6955.0 & & 7318.9 & 5843.3 & 6957.4 & 5941.2 & 15765.0 & 8476.4 \\
\hline $\begin{array}{r}\text { Average Page Download Speed (kbps) } \\
{[\text { Higher is better] }}\end{array}$ & 2026.3 & & 1989.6 & 4738.8 & 2676.2 & 4322.1 & 2191.7 & 4025.3 \\
\hline $\begin{array}{l}\text { Average Ping Average RTT (ms) } \\
\text { [Lower is better] }\end{array}$ & 84.1 & 50.4 & 107.3 & 84.9 & 122.2 & 96.8 & 125.8 & 118.2 \\
\hline $\begin{array}{r}\text { Average Cellular Signal Strength }(\mathrm{dBm}) \\
{[\text { Higher is better] }}\end{array}$ & -86.0 & -92.5 & -85.7 & -91.45 & -81.3 & -85.7 & -82.4 & \\
\hline
\end{tabular}

\begin{tabular}{|l|l|l|}
\hline Morphology: Suburban & Operator: $Y$ & MBB service: WEB \\
\hline
\end{tabular}

\begin{tabular}{|c|c|c|c|c|c|c|c|c|}
\hline & \multicolumn{2}{|c|}{ KV } & \multicolumn{2}{|c|}{ JOHOR } & \multicolumn{2}{|c|}{ SABAH } & \multicolumn{2}{|c|}{ SARAWAK } \\
\hline & $3 G$ & 4G & $3 G$ & $4 G$ & $3 G$ & 4G & $3 G$ & 4G \\
\hline $\begin{array}{l}\text { Overall Page Display Success Ratio } \\
\text { [Higher is better] }\end{array}$ & 0.72 & 0.99 & 0.70 & 0.97 & 0.82 & 0.96 & 0.99 & \\
\hline $\begin{array}{l}\text { Average Page Response Latency (ms) } \\
\text { [Lower is better] }\end{array}$ & 2521.0 & 583.5 & 1450.5 & 742.5 & 1736.6 & 944.5 & 2409.0 & 691.0 \\
\hline $\begin{array}{c}\text { Average Page Display Latency (ms) } \\
\text { [Lower is better] }\end{array}$ & 6827.1 & 5026.8 & 6937.5 & 5869.1 & 6998.0 & 6103.3 & 19085.1 & 7682.0 \\
\hline $\begin{array}{r}\text { Average Page Download Speed (kbps) } \\
\text { [Higher is better] }\end{array}$ & 1461.2 & 5954.2 & 2083.8 & 5992.2 & & 4165.3 & 699.9 & 4712.5 \\
\hline $\begin{array}{l}\text { Average Ping Average RTT (ms) } \\
\text { [Lower is better] }\end{array}$ & 133.2 & 42.4 & 110.6 & 55.2 & 124.7 & 91.5 & 137.8 & 67.5 \\
\hline $\begin{array}{r}\text { Average Cellular Signal Strength (dBm) } \\
\text { [Higher is better] }\end{array}$ & -87.8 & -89.9 & -80.1 & -87.1 & -86.0 & -85.3 & & -86.3 \\
\hline Morphology: Suburban & & or: $Z$ & & & MBB $\mathrm{s}$ & e: WEB & & \\
\hline
\end{tabular}

\begin{tabular}{|c|c|c|c|c|c|c|c|c|}
\hline & \multicolumn{2}{|c|}{ KV } & \multicolumn{2}{|c|}{ JOHOR } & \multicolumn{2}{|c|}{ SABAH } & \multicolumn{2}{|c|}{ SARAWAK } \\
\hline & $3 G$ & 4G & $3 G$ & 4G & $3 G$ & 4G & $3 G$ & $4 G$ \\
\hline $\begin{array}{r}\text { Overall Page Display Success Ratio } \\
\text { [Higher is better] }\end{array}$ & 0.63 & 0.98 & 0.68 & 0.93 & 0.82 & 0.96 & 1.00 & 1.00 \\
\hline $\begin{array}{r}\text { Average Page Response Latency (ms) } \\
{[\text { Lower is better] }}\end{array}$ & 2663.0 & 609.0 & 1812.8 & 726.7 & 1359.0 & 958.5 & 1028.6 & 685.1 \\
\hline $\begin{array}{r}\text { Average Page Display Latency (ms) } \\
\text { [Lower is better] }\end{array}$ & 6386.7 & 4787.5 & 6305.0 & 5667.1 & 7202.9 & 6251.7 & 17223.1 & 7681.3 \\
\hline $\begin{array}{r}\text { Average Page Download Speed (kbps) } \\
\text { [Higher is better] }\end{array}$ & 1128.0 & 5932.0 & 2521.3 & 4956.3 & 2830.8 & 4091.4 & 2056.2 & 4347.8 \\
\hline $\begin{array}{r}\text { Average Ping Average RTT (ms) } \\
\text { [Lower is better] }\end{array}$ & 81.0 & 46.8 & 69.9 & 59.4 & 113.4 & 101.3 & 90.3 & 74.0 \\
\hline $\begin{array}{r}\text { Average Cellular Signal Strength }(\mathrm{dBm}) \\
{[\text { Higher is better] }}\end{array}$ & -82.1 & -90.6 & -88.3 & -88.4 & -83.5 & -87.3 & -84.3 & -84.9 \\
\hline
\end{tabular}




\section{PERFORMANCE OF VIDEO STREAMING}

The performance of both $3 \mathrm{G}$ and $4 \mathrm{G}$ were assessed in terms of video streaming. The performance for both networks was evaluated in each testing area. For unbiased outcomes, the same time and area were used in the assessment of network of each of the 3MNOs. Moreover, the assessment involved use of only generic and unmodified smart phones running similar operating systems so as to prevent bias in outcomes. The assessment was done in suburban morphologies using Samsung Galaxy S6 smartphones which revealed no use of $2 \mathrm{G}$ and sole dependence of users on $3 \mathrm{G}$ and $4 \mathrm{G}$ networks.

The network performance in context of video streaming is considered in this assessment. This assessment involved the assessment of a number of KPIs.

\section{A. Network Signal Coverage for Video}

In this part of the article, the VIDEO streaming experience was assessed to evaluate the network signal coverage. The network signal coverage is measured by the cellular signal strength. Figures 14 and 15 depict the performance of $4 \mathrm{G}$ and $3 \mathrm{G}$ technologies accordingly with respect to their cellular signal strength distribution when using video streaming applications. Moreover, assessing the performance of the 3 network service providers in the domain of video streaming through 4G networks, the performance of the service providers $\mathrm{X}$ and $\mathrm{Z}$ apparently outshined that of $\mathrm{Y}$ service provider in each testing site as seen in Figure 14. Similarly, considering the performance of service providers in $3 \mathrm{G}$ technology in 4 testing sites, the network operator $\mathrm{Y}$ outperformed $\mathrm{X}$ and $\mathrm{Z}$. A contrast of $4 \mathrm{G}$ and $3 \mathrm{G}$ technologies in terms of network signal coverage at Johor, Sarawak and Klang Valley as depicted in Figure 14 with Figure 15. In the area of Sabah, $3 \mathrm{G}$ networks provided more strong signals than 4G. Moreover, assessment revealed that $4 \mathrm{G}$ signals proved to be stronger than $3 \mathrm{G}$ ones in other areas; however, the significance of $3 \mathrm{G}$ signals cannot be undermined since these offer support to the $4 \mathrm{G}$ networks by connecting various $4 \mathrm{G}$ overage areas thus serving the purpose of backbone or core network.

Figure 15 depicts the range of signal power of $4 \mathrm{G}$ networks received in 4 states which is from $-110 \mathrm{dBm}$ to $-50 \mathrm{dBm}$. But, as far as recorded signal strength is concerned, it ranged from $-105 \mathrm{dBm}$ to $-75 \mathrm{dBm}$. Conversely, the range of signal strength of $3 \mathrm{G}$ networks in the 4 states was from $-110 \mathrm{dBm}$ to $-30 \mathrm{dBm}$ as per the same figure while the recorded strength ranged from $-100 \mathrm{dBm}$ to $-60 \mathrm{dBm}$. The results also revealed the outperformance of $3 \mathrm{G}$ networks by the $4 \mathrm{G}$ networks not only in received signal strength but also in terms of the number of recorded access cycles. The difference was found to exceed $200 \%$. Moreover, Johor was the area found to have received highest number of access cycles for each kind of network.

\section{B. Network Satisfaction for Video}

The network signal strength may be evaluated in suburban morphologies within the 4 states by presenting the ratio between the total requests for total video access made and the total access of video streaming. The total number of cycles attempts made for watching and streaming videos are termed as total video access attempts while the ratio of total watched videos to the number of video access attempts is termed as overall video access ratio. This ratio can be used as a KPI for evaluation of performance of the network signal. In case of web browsing, the evaluation can be done by determining the ratio of successfully viewed web page to the browsing attempts.

In this study, various attempts were made to get access to video services. The Samsung Galaxy S6 was used in all the attempts to determine the video streaming performance. The results have been presented in Figure 16. The results showed that $4 \mathrm{G}$ technology allowed $67.1 \%$ access to video services in Klang Valley region, $71.7 \%$ successful access to video services in Johor, $62.8 \%$ access in Sabah and $73.4 \%$ access in Sarawak region. The $4 \mathrm{G}$ networks allowed greater number of successful video access attempts than the $3 G$ network probably owing to expansive deployment of $4 \mathrm{G}$ networks and higher resourcefulness associated with these networks.

The video access ratio evaluated for suburban morphologies in all the 4 states have been depicted in Figure 17. The outcomes showed video access ratio from 0 to1 $(0,1)$. Simply, the video access ratio is higher at the value of 1 and lowest at 0 . Moreover, when using $3 \mathrm{G}$ technology, the range of video access ratio was found to be from 0.82 to 0.983 for all states and service providers as per Figure 17. Conversely, when using 4G services, all the states and service providers depicted the video access ratio between 0.995 and 1 . Hence, it can be said that irrespective of the state and MNOs (measured in this study), the performance depicted by $4 \mathrm{G}$ networks outshined that of $3 \mathrm{G}$ in terms of video access ratios.

\section{C. $v M O S$}

Another KPI of vMOS will be employed in this part of the study to evaluate the performance of network. The HUAWEIdeveloped KPI will evaluate the video quality and thus help in assessment of performance of networks in terms of video services provided by these networks.

The network performance was evaluated in terms of the vMOS scores of each included MNO on the basis of technological classification as evident from Figure 18. Statewise outcomes of vMOS were also stated. In suburban morphologies, each of the 3included MNOs depicted higher scores and consequently better performance in the $4 \mathrm{G}$ networks than the $3 \mathrm{G}$ networks.

The scores of vMOS noted for $4 \mathrm{G}$ networks were found between 3.12 and 3.63. Conversely, the scores for $3 \mathrm{G}$ were found between 1.31 and 2.64. This may be attributed to a couple of things: $4 \mathrm{G}$ networks have a wide deployment and better coverage; moreover, the resourcefulness of $4 \mathrm{G}$ networks is far greater than those $3 \mathrm{G}$ networks.

\section{Network Download Speed for Video}

In this part of the study, the network download speed will be discussed in context of video services. The network download speed will be evaluated as average rate of video download in the suburban areas of the considered states. Such data includes webpages, applications, games and videos. The download speed varied with each mobile technology. Download speed may be defined as the rate of data transfer between source and 

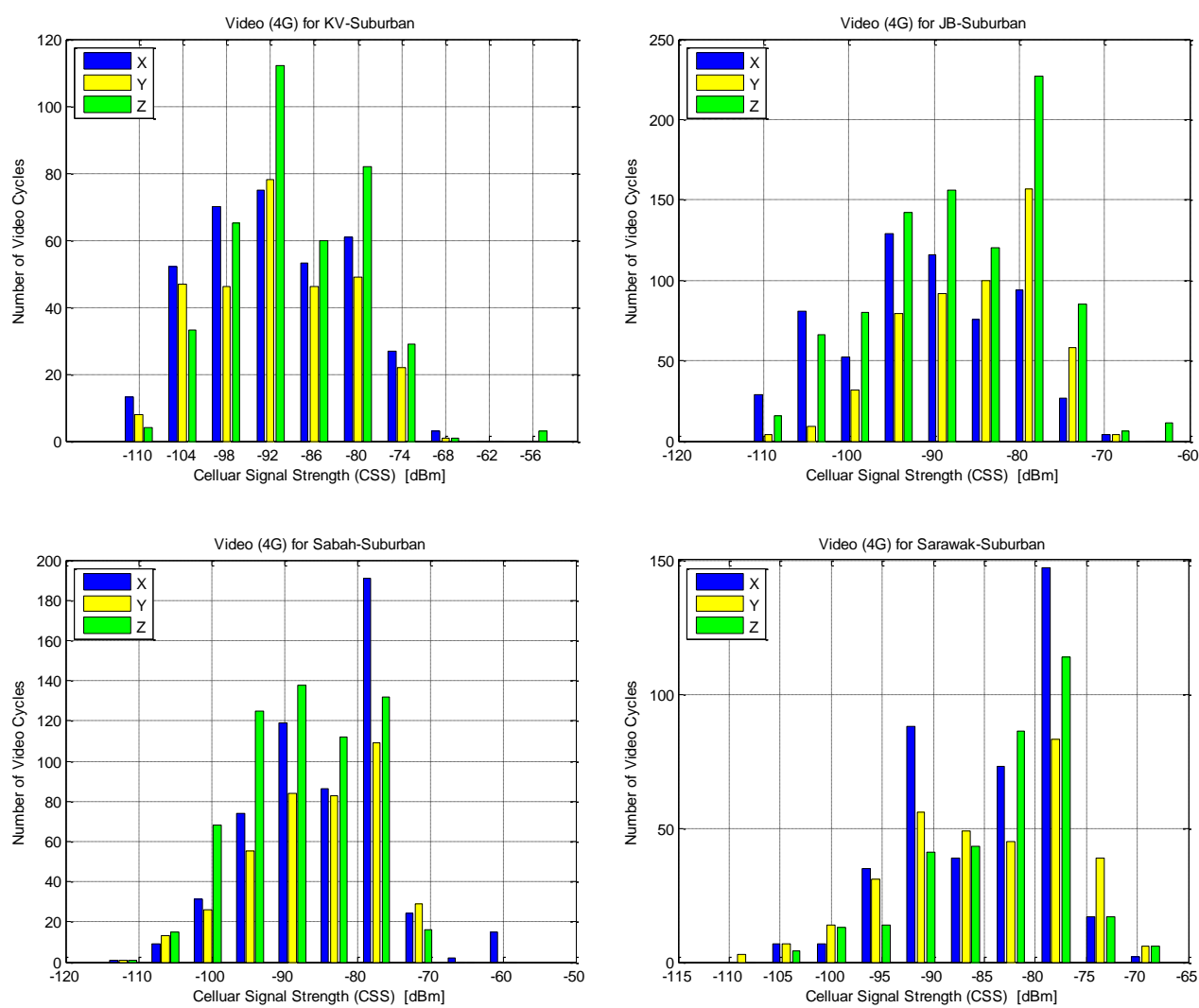

Fig.15. PDF of the received cellular signal strength of $4 \mathrm{G}$ mobile technology for video streaming measured at four different suburban morphologies
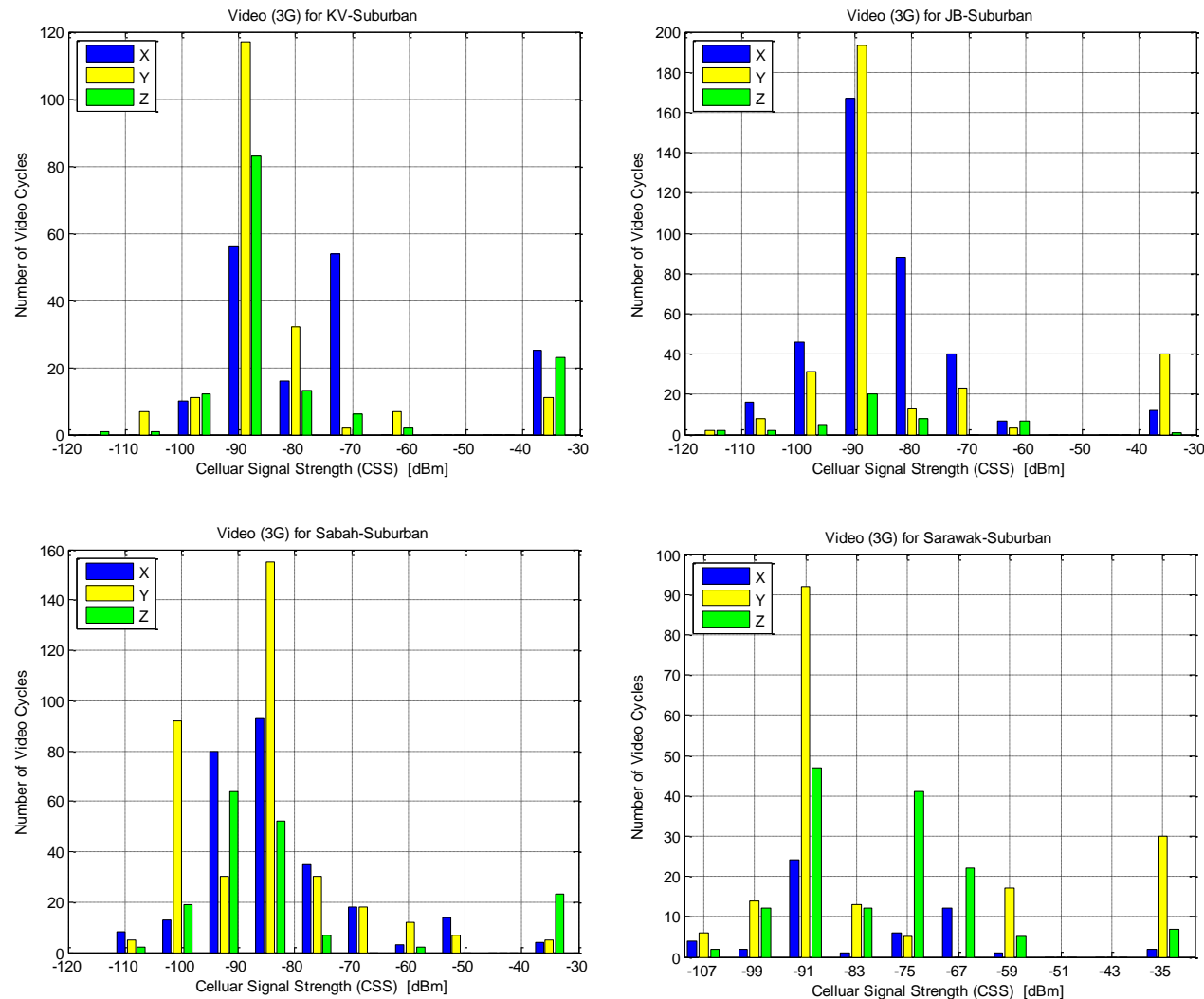

Fig.16. PDF of the received cellular signal strength of $3 \mathrm{G}$ mobile technology for video streaming measured at four different suburban morphologies 
The $\mathbf{8 0} \%$ of the measured coverage in the tested suburban morphologies is stronger than the given video cellular signal strength stated in this table.

\begin{tabular}{|c|c|c|c|c|c|}
\hline \multirow{2}{*}{ MNO } & \multirow{3}{*}{ Network type } & \multicolumn{3}{|c|}{ Area } \\
\cline { 3 - 6 } & & Klang Valley & \multirow{2}{*}{ Johor } & Sabah & \\
\hline \multirow{2}{*}{$\mathrm{X}$} & $4 \mathrm{G}$ & $-100 \mathrm{dBm}$ & $-101 \mathrm{dBm}$ & $-92 \mathrm{dBm}$ & $-92 \mathrm{dBm}$ \\
\cline { 2 - 6 } & $3 \mathrm{G}$ & $-87.6 \mathrm{dBm}$ & $-91 \mathrm{dBm}$ & $-91 \mathrm{dBm}$ & $-89 \mathrm{dBm}$ \\
\hline \multirow{2}{*}{$\mathrm{Y}$} & $4 \mathrm{G}$ & $-100 \mathrm{dBm}$ & $-92 \mathrm{dBm}$ & $-93 \mathrm{dBm}$ & $-92 \mathrm{dBm}$ \\
\cline { 2 - 6 } & $3 \mathrm{G}$ & $-91 \mathrm{dBm}$ & $-91 \mathrm{dBm}$ & $-103 \mathrm{dBm}$ & $-91 \mathrm{dBm}$ \\
\hline \multirow{2}{*}{$\mathrm{Z}$} & $4 \mathrm{G}$ & $-96 \mathrm{dBm}$ & $-96 \mathrm{dBm}$ & $-95 \mathrm{dBm}$ & $-89.9 \mathrm{dBm}$ \\
\cline { 2 - 6 } & $3 \mathrm{G}$ & $-91 \mathrm{dBm}$ & $-94 \mathrm{dBm}$ & $-91 \mathrm{dBm}$ & $-89 \mathrm{dBm}$ \\
\hline
\end{tabular}

mobile phone. In this study, we will focus on video downloads speed in the four considered states to analyze the network performance in terms of video download speeds for both $3 \mathrm{G}$ and $4 \mathrm{G}$ networks.

The total average video download rate was calculated for each of the 4 included states and presented in Figure 19. In suburban areas, 4G significantly outperformed $3 \mathrm{G}$ and was found to depict about 1.32 times higher video download speed than $3 \mathrm{G}$ in Klang Valley, 1.23 times in Johor, 1.35 times in Sabah and 1.24 times in Sarawak regions. This implies that the faster video download rate enable $4 \mathrm{G}$ users to download their desired content without long hours of wait and disruptions and allows them to instantly download and view some web page.

Hence, 4G users do not have to face buffering and interruptions during their video streaming which is usually the case in $3 \mathrm{G}$ networks. In $4 \mathrm{G}$ networks, the 3 included service providers $\mathrm{X}, \mathrm{Y}$ and $\mathrm{Z}$ depicted different values of average download speeds which are as follows: $X$ (1.86 Mbps), $\mathrm{Y}(1.94 \mathrm{Mbps})$ and $\mathrm{Z}(1.83 \mathrm{Mbps})$. Conversely, the same service providers depicted the following speeds for video services; X (1.48Mbps), Y (1.53Mbps) and Z (1.49Mbps). This implies better performance and faster download speed of $4 \mathrm{G}$ in contrast with $3 \mathrm{G}$ in context of video services.

\section{E. Network Latency for Video}

While comparing the average initial buffering latency for both $3 \mathrm{G}$ and $4 \mathrm{G}$ networks, it was found that $4 \mathrm{G}$ outperformed $3 \mathrm{G}$ by a significant margin for each MNO considered in the study. The use of $4 \mathrm{G}$ network rendered the average latency values of $1220.7 \mathrm{~ms}, 1378.5 \mathrm{~ms}, 1787.5 \mathrm{~ms}$, and $1654.63 \mathrm{~ms}$ for the regions of Klang Valley, Johor, Sabah and Sarawak. Conversely, the $3 \mathrm{G}$ network rendered the average latency values of $13076.2 \mathrm{~ms}, 6618.5 \mathrm{~ms}, 8653.9 \mathrm{~ms}$ and $8428.1 \mathrm{~ms}$ for the regions of Klang Valley, Johor, Sabah and Sarawak. The average values were based on the latency values obtained from all the 3 MNOs.

It was also revealed that $4 \mathrm{G}$ network again outperformed $3 \mathrm{G}$ networks with its lower average video E2E RTT-Ping server latency. 4G networks rendered average latency values of $45.2 \mathrm{~ms}$ for Klang Valley, $52.7 \mathrm{~ms}$ for Johor, $74.3 \mathrm{~ms}$ for Sabah, and 69.9 ms for Sarawak. Conversely, the 3G networks rendered average latency values of $838.2 \mathrm{~ms}$ for Klang Valley, $282.7 \mathrm{~ms}$ for Johor, $413.2 \mathrm{~ms}$ for Sabah and $521.1 \mathrm{~ms}$ for Sarawak. The average values were based on the values obtained for all MNOs.

All the 3 included MNOs across all the included states rendered lower total re-buffering latency values for $4 \mathrm{G}$ networks. However, only the operator Y at suburban Sarawak rendered higher latency values with $4 \mathrm{G}$ in contrast with $3 \mathrm{G}$ networks. The 4G network rendered the values of $3870.6 \mathrm{~ms}$ for Klang Valley, $4111.0 \mathrm{~ms}$ for Johor, $5747.1 \mathrm{~ms}$ for Sabah, and $11214.1 \mathrm{~ms}$ for Sarawak. The average values were based on the values obtained from all the considered networks from the 4 test states. For $3 \mathrm{G}$ networks, the obtained average latency values were $19113.2 \mathrm{~ms}$ for Klang Valley, $11460.0 \mathrm{~ms}$ for Johor, $13737.8 \mathrm{~ms}$ for Sabah and $10534.6 \mathrm{~ms}$ for Sarawak.

The network; latency is a significant factor in networking. It determines the quality of experience enjoyed by a user. There are various kinds of latencies including initial buffering latency, initial E2E RTT-Ping server latency and re-buffering latency. All these latency types will be covered subsequently. The network latency is defined as the delay in the initial server response to a request made by the user to transfer data from source to device. User is only enabled to download something from the internet when the server allows it by responding to it. The server response initiates the downloading process immediately. Figure 20 shows the average video initial buffering latency, Figure 21 shows the average video initial E2E RTT-Ping server latency and finally Figure 22 shows the average video total re-buffering latency.

The average value of initial video buffering latency was determined for all the 3 MNOs across all the 4 states. The values obtained are shown in Figure 20. These values indicated that $4 \mathrm{G}$ outperformed $3 \mathrm{G}$ in terms of average initial buffering latency in each of the 3 considered MNOs. The average of the latency values of all networks in a specific region was found; Klang Valley region showed an average latency of $1220.7 \mathrm{~ms}$, Johor showed an average of $1378.5 \mathrm{~ms}$, Sabah rendered average of $1787.5 \mathrm{~ms}$ and Sarawak gave average values of $1654.63 \mathrm{~ms}$ when using 4G. Conversely the use of $3 \mathrm{G}$ networks depicted average latency values of $13076.2 \mathrm{~ms}, 6618.5 \mathrm{~ms}, 8653.9 \mathrm{~ms}$ and $8428.1 \mathrm{~ms}$ in Klang Valley, Johor, Sabah and Sarawak regions accordingly. Moreover, the same areas and MNOs were again evaluated for the values of average video's initial E2E RTT-Ping server latency for $3 \mathrm{G}$ and $4 \mathrm{G}$ networks. These values have been depicted in Figure 21. The results indicated lower values of average video E2E RTT-Ping server latency for $4 \mathrm{G}$ in comparison to $3 \mathrm{G}$ networks. Similarly, in comparison to $3 \mathrm{G}$, lower values of average video E2E RTT-Ping server latency was recorded for $4 \mathrm{G}$ networks. Moreover, the average latency value evaluated for $4 \mathrm{G}$ networks for each of the 4 included states were $45.2 \mathrm{~ms}$ for Klang Valley, $52.7 \mathrm{~ms}$ for Johor, 74.3 $\mathrm{ms}$ for Sabah, and $69.9 \mathrm{~ms}$ for Sarawak. On the other hand, the average latency value for $3 \mathrm{G}$ were found to be $838.2 \mathrm{~ms}$ for Klang, $282.7 \mathrm{~ms}$ for Johor, $413.2 \mathrm{~ms}$ for Sabah and 521.1 ms for Sarawak. 

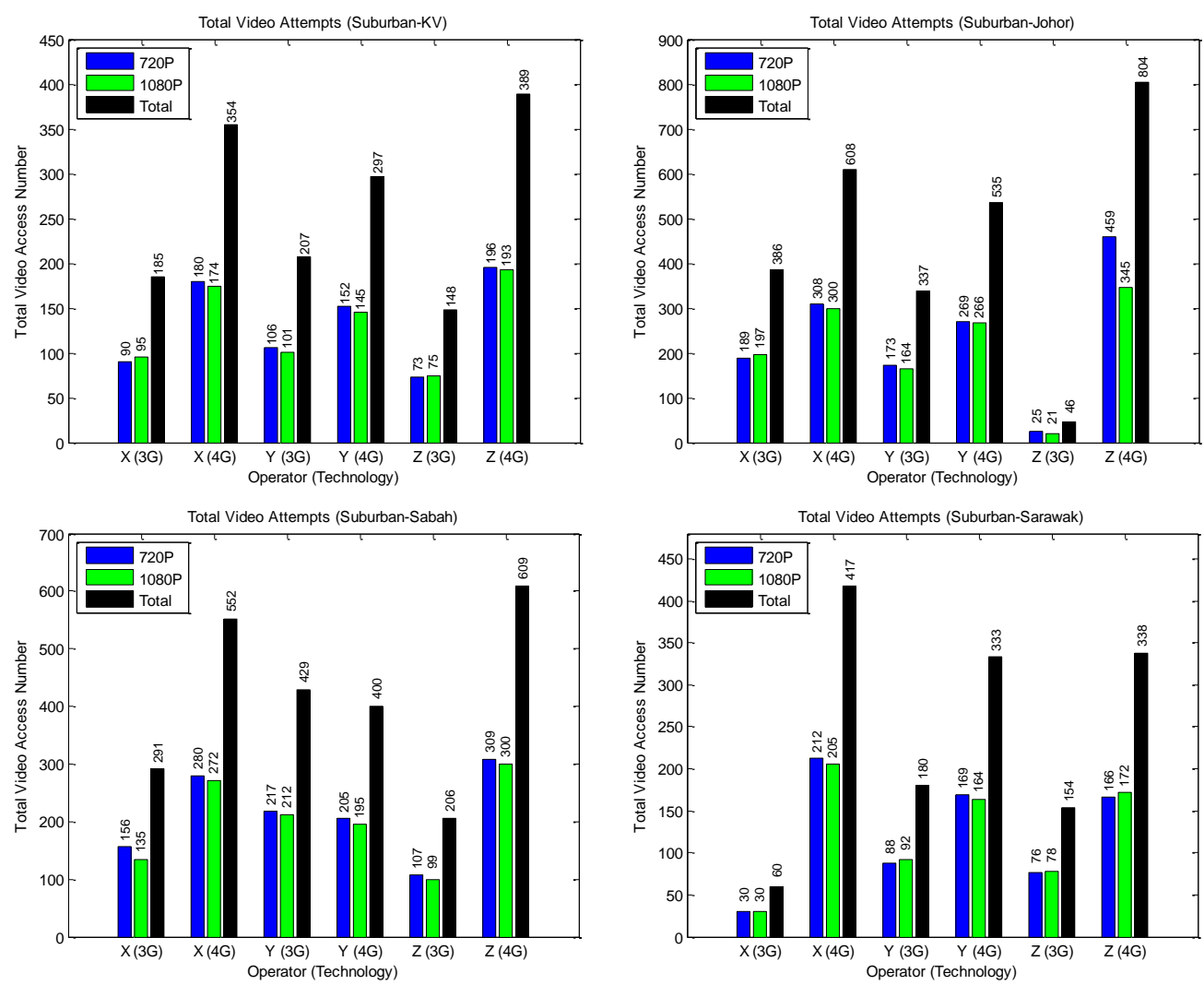

Fig.17. The total video access attempt measured at four different suburban morphologies and classified based on mobile technologies, MNOs and morphologies.
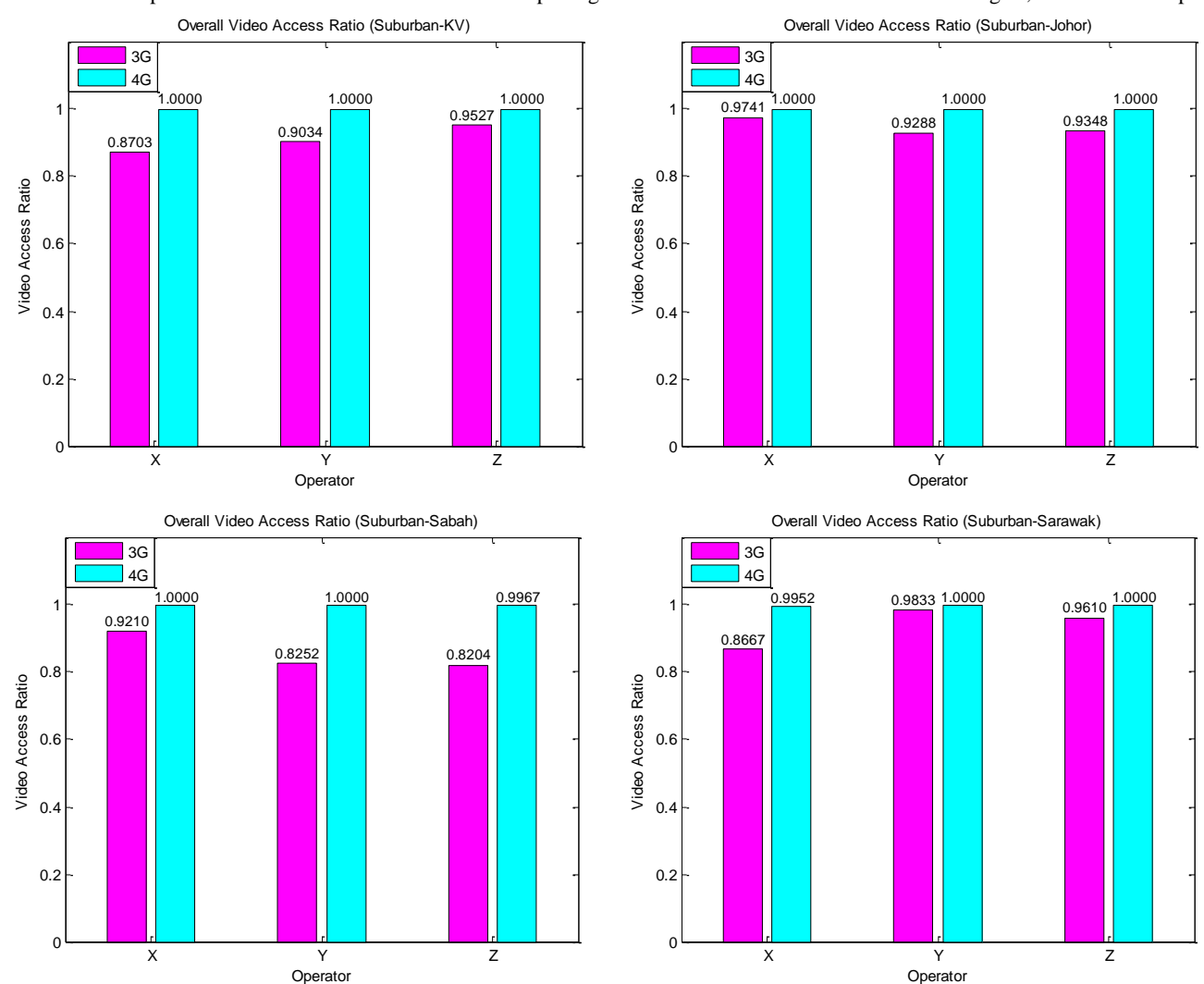

Fig.18. The overall video access ratio measured at four different suburban morphologies located in four different states 

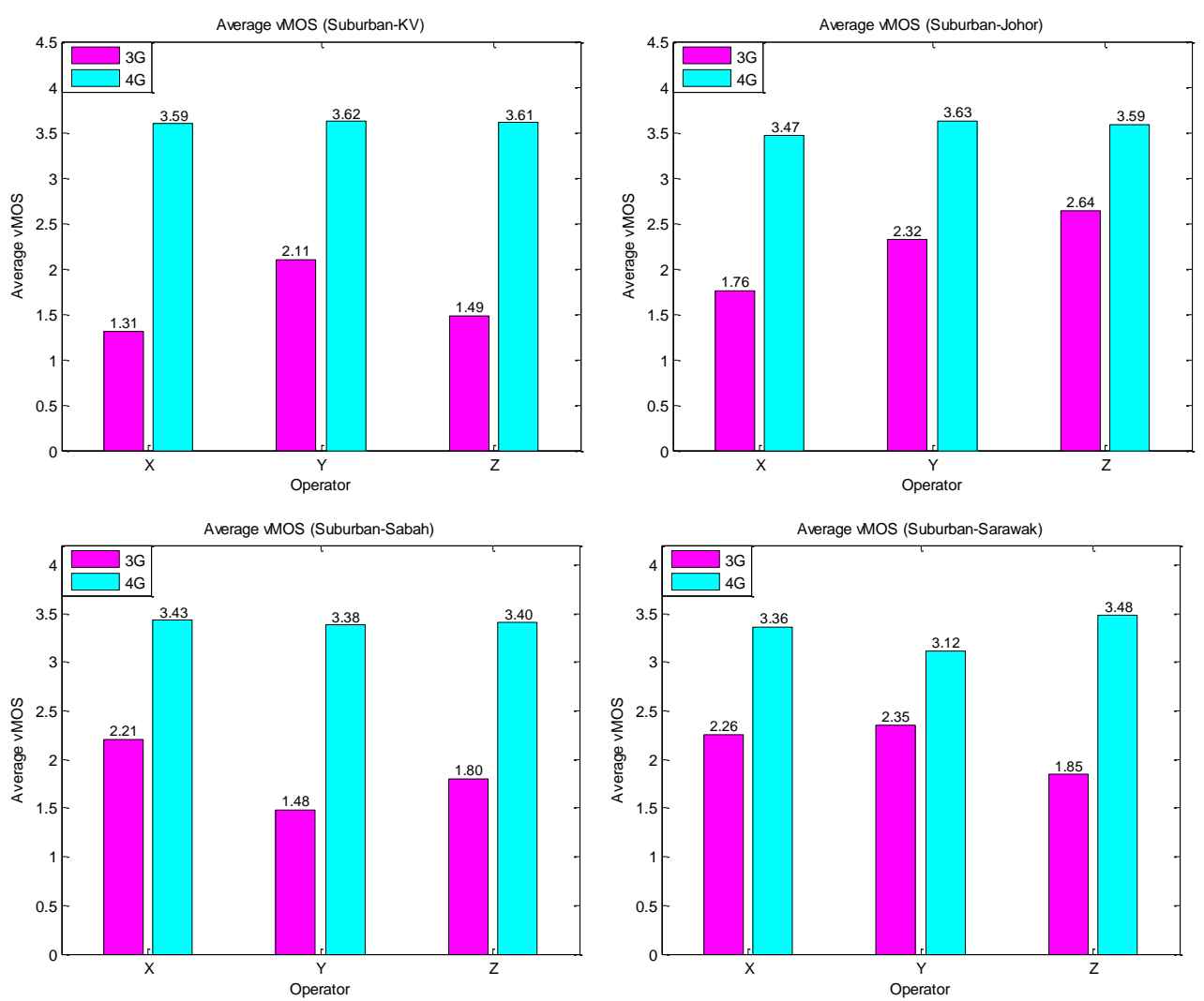

Fig.19. vMOS score measured at four different suburban morphologies located in four different states, and categorized based on technologies \#
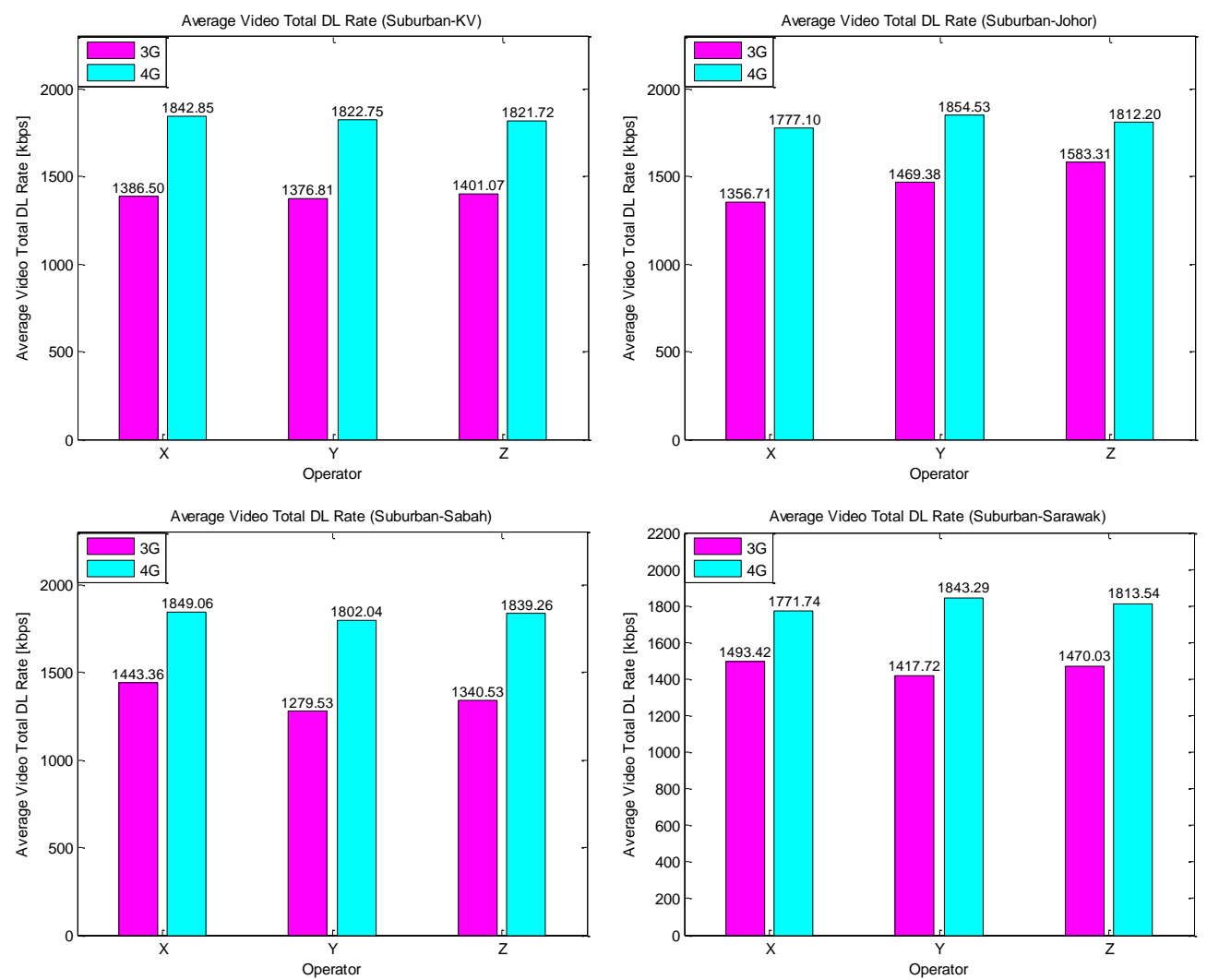

Fig.20. The average video total download rate measured at four different suburban morphologies located in four different states, and categorized based on technologies 

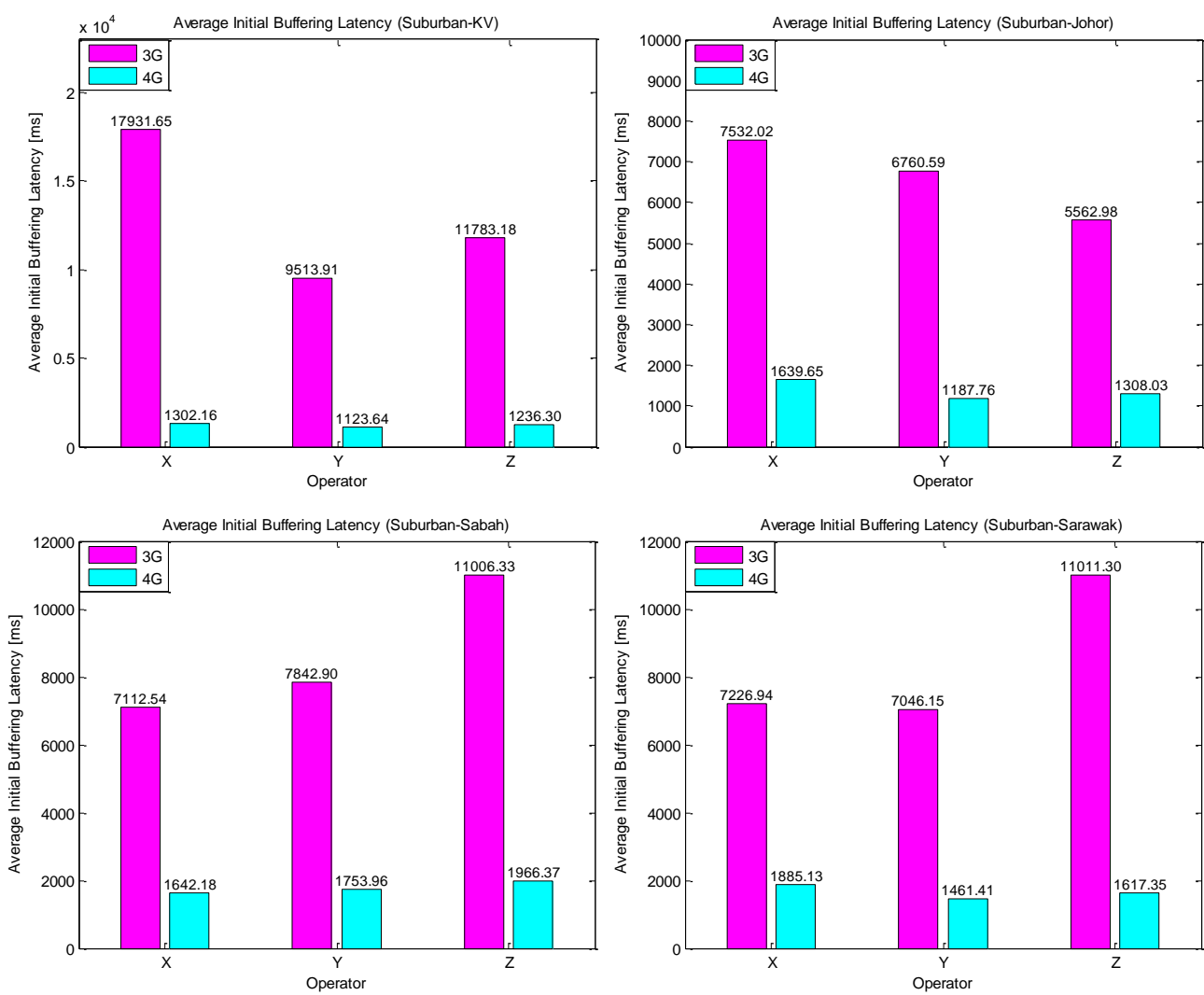

Fig.21. The average of video initial buffering latency measured at four different suburban morphologies located in four different states, and categorized based on technologies
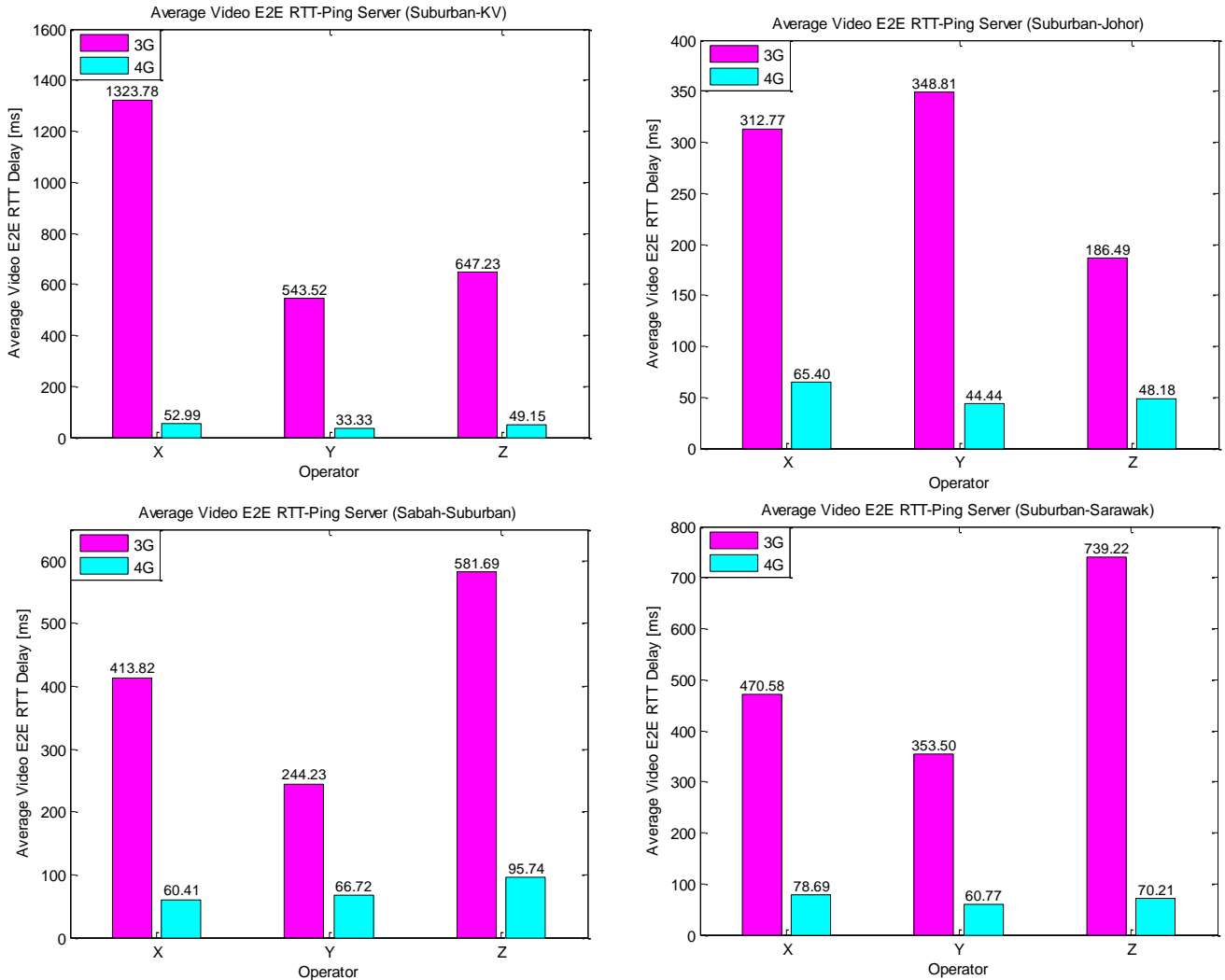

Fig.22. The average of video initial E2E RTT-Ping server latency measured at four different suburban morphologies located in four different states, and categorized based on technologies 
The average video's total re-buffering latency values recorded in all states and for all MNOs are given in Figure 22. It is evident from the figure that the values recorded for average total re-buffering latency in $4 \mathrm{G}$ networks are lower than in $3 \mathrm{G}$ networks. However, the MNO $\mathrm{Y}$ showed a different result in suburban Sarawak. 4G networks showed overall average latency values of $3870.6 \mathrm{~ms}$ for all tested networks in Klang Valley, $4111.0 \mathrm{~ms}$ in Johor, $5747.1 \mathrm{~ms}$ in Sabah, and $11214.1 \mathrm{~ms}$ in Sarawak. On the other hand, the $3 \mathrm{G}$ network depicted values of $19113.2 \mathrm{~ms}$ in Klang Valley, $11460.0 \mathrm{~ms}$ in Johor, $13737.8 \mathrm{~ms}$ in Sabah and $10534.6 \mathrm{~ms}$ in Sarawak. The novel technologies associated with IoT and Big Data require high-speed transfer of data which can be achieved through low-latency communications. These technologies will not be effective in case of absence of low latency leading to inferior service quality and unsatisfied user.

\section{F. Summary For Video}

The performance of networks in terms of quality of video services was evaluated and the results have been tabulated in Table 4. The services were provided in the suburban morphology by the three MNOs considered in the study. The MNOs were denoted by X, Y and Z. The values were obtained by applying $8 \mathrm{KPIs}$ to four different states for both $3 \mathrm{G}$ and $4 \mathrm{G}$.

The values obtained have been subjected to horizontal and vertical analysis for comparison as shown in the table. The blue and red boxes indicate the values to be compared.

As horizontal comparison of the measurement findings is presented across the four states for the same operators, technology and KPIs, where the table legend includes blue box and red box colors.
According to Operator $\boldsymbol{X}$ performance, for $4 \mathrm{G}$ technology, the operator $X$ offered the best performance in $\mathrm{KV}$ state much better than the other all states. But for $3 G$ technology, the Operator X offered the best performance in Sarawak state better than the other states.

According to Operator $\boldsymbol{Y}$ performance, for $4 \mathrm{G}$ technology, the operator $\mathrm{Y}$ offered the best performance in $\mathrm{KV}$ and Johor states much better than the other all states. But for $3 \mathrm{G}$ technology, the Operator $\mathrm{Y}$ offered the best performance in JOHOR and SARAWAK states better than the other states.

According to Operator $Z$ performance, for $4 \mathrm{G}$ technology, the operator $\mathrm{Z}$ offered the best performance in $\mathrm{KV}$ state much better than the other all states. But for $3 \mathrm{G}$ technology, the Operator $\mathrm{Z}$ offered the best performance in JOHOR state better than the other states.

The vertical analysis of the values is followed by horizontal analysis to compare the network performance of a specific MNO, applying the same KPI and same network in different states. From the comparison between the operators for the both technologies, it can be seen that for $4 \mathrm{G}$ technology operator $\mathrm{Y}$ offered better overall performance compared to $\mathrm{X}$ and $\mathrm{Z}$ operators, with respect to video services overall states. That has been indicated by green circle around the highest values over all operators. Low 4G performance is exhibited overall by operator $\mathrm{X}$ as compared to operators $\mathrm{Y}$ and $\mathrm{Z}$. On the contrary, it can be also seen that for $3 \mathrm{G}$ technology operator $\mathrm{Z}$ offered better overall performance compared to $\mathrm{X}$ and $\mathrm{Y}$ operators, with respect to video services overall states. That has been indicated by pink circle around the highest values over all operators. Low $3 \mathrm{G}$ performance is exhibited overall by operator $\mathrm{X}$ and $\mathrm{Y}$ as compared to operator $\mathrm{Z}$.
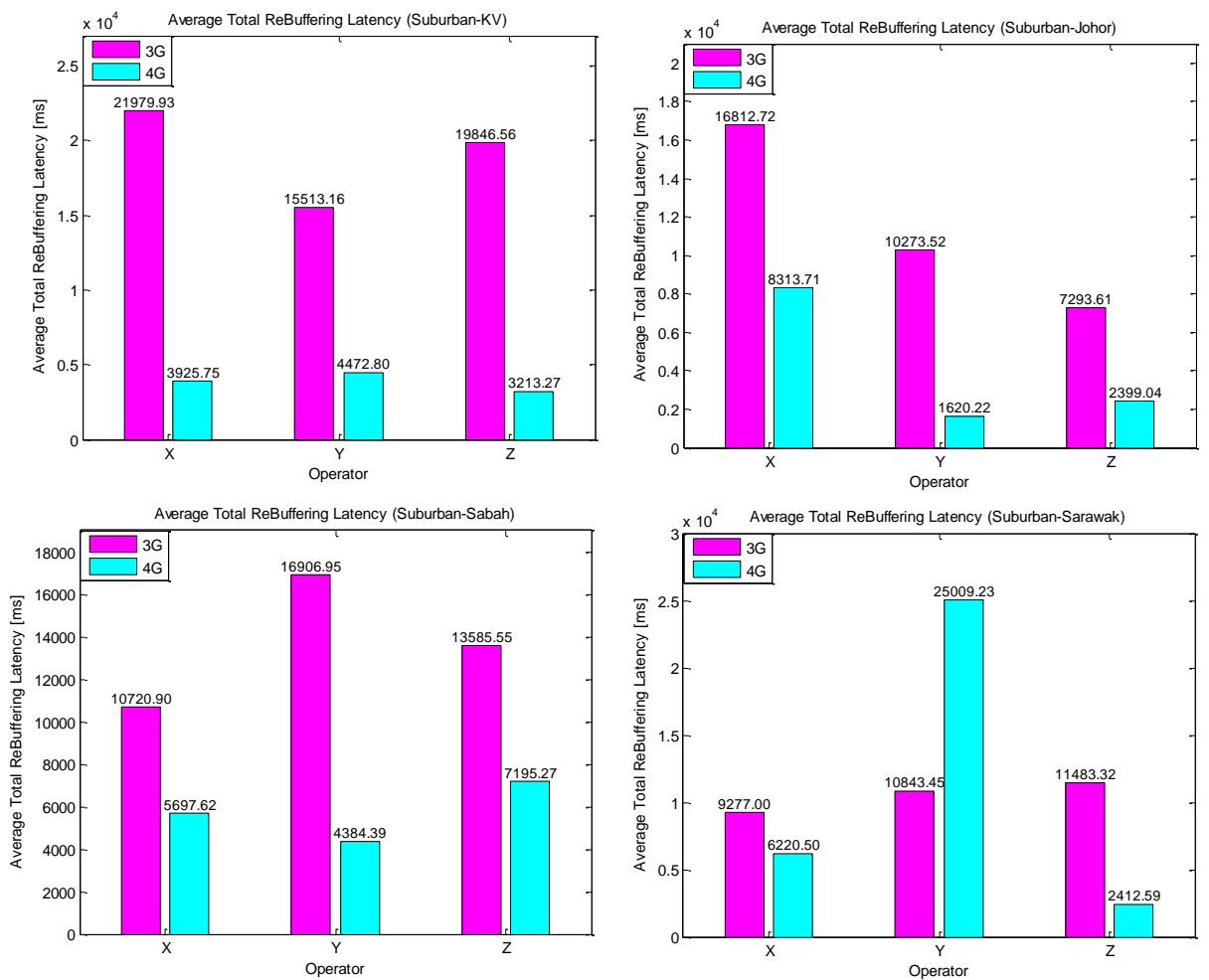

Fig.23. The average of video total re-buffering latency measured at four different suburban morphologies located in four different states, and categorized based on technologies 
TABLE 2. The final summary of video services measured at four different suburban morphologies located in four different states, and categorized based on technologies

(a)

\begin{tabular}{|c|c|c|c|c|c|c|c|c|}
\hline \multirow[t]{3}{*}{ Morphology: Suburban } & \multicolumn{4}{|c|}{ Operator: $\mathrm{X}$} & \multicolumn{4}{|c|}{ MBB service: VIDEO } \\
\hline & \multicolumn{2}{|c|}{ KV } & \multicolumn{2}{|c|}{ JOHOR } & \multicolumn{2}{|c|}{ SABAH } & \multicolumn{2}{|c|}{ SARAWAK } \\
\hline & $3 G$ & $4 G$ & $3 G$ & $4 G$ & $3 G$ & 4G & $3 G$ & $4 G$ \\
\hline $\begin{array}{l}\text { Initial Buffering Success Ratio } \\
\text { [Higheris better] }\end{array}$ & 0.87 & 1.00 & 0.97 & & 0.92 & $1.00)$ & 0.87 & 1.00 \\
\hline $\begin{array}{l}\text { Average vMOS Score } \\
{[\text { Range }=1 \text { to } 5] \quad \text { [Higher is better] }}\end{array}$ & 1.31 & 3.59 & 1.76 & 3.47 & 2.21 & 3.43 & 2.26 & 3.36 \\
\hline $\begin{array}{l}\left.\begin{array}{l}\text { Average Video Total Download Rate } \\
\text { (kbps) }\end{array}\right] \text { [Higheris better] }\end{array}$ & 1386.5 & 1842.9 & 1356.7 & 1777.1 & 1443.4 & 1849.1 & 1493.4 & 1771.7 \\
\hline $\begin{array}{ll}\text { Average Video Maximum Download } \\
\text { Rate (kbps) }\end{array}$ & 6074.1 & 19736.2 & 5405.1 & 15036.7 & 5773.0 & 17055.6 & 6165.5 & 15781.7 \\
\hline $\begin{array}{r}\text { Average Initial Buffering Latency (ms) } \\
\text { [Lower is better] }\end{array}$ & 17931.7 & 1302.2 & 7532.0 & 1639.7 & 7112.5 & 1642.2 & 7226.9 & 1885.1 \\
\hline $\begin{array}{c}\text { Average Video E2E RTT Ping (ms) } \\
\text { [Lower is better] }\end{array}$ & 1323.8 & 53.0 & 312.8 & 65.4 & 413.8 & 60.4 & 470.6 & 78.7 \\
\hline $\begin{array}{l}\begin{array}{l}\text { Average Total Re-buffering Latency } \\
\text { (ms) } \\
\text { [Loweris better] }\end{array}\end{array}$ & 21980.0 & 3925.8 & 16812.7 & 8313.7 & 10720.9 & 5697.6 & 9277.0 & 6220.5 \\
\hline $\begin{array}{r}\text { Average Cellular Signal Strength (dBm) } \\
{[\text { Higheris better }]}\end{array}$ & & -90.4 & -84.3 & -91.0 & -82.9 & -84.5 & -80.6 & -84.6 \\
\hline
\end{tabular}

(b)

\begin{tabular}{|c|c|c|c|c|c|c|c|c|}
\hline \multirow[t]{3}{*}{ Morphology: Suburban } & \multicolumn{4}{|c|}{ Operator: $Y$} & \multicolumn{4}{|c|}{ MBB service: VIDEO } \\
\hline & \multicolumn{2}{|c|}{ KV } & \multicolumn{2}{|c|}{ JOHOR } & \multicolumn{2}{|c|}{ SABAH } & \multicolumn{2}{|c|}{ SARAWAK } \\
\hline & $3 G$ & $4 G$ & $3 G$ & 46 & $3 G$ & 46 & $3 G$ & 46 \\
\hline $\begin{array}{l}\text { Initial Buffering Success Ratio } \\
\text { [Higheris better] }\end{array}$ & 0.90 & & 0.93 & & 0.83 & & & \\
\hline $\begin{array}{l}\text { Average vMOS Score } \\
{[\text { Range }=1 \text { to } 5] \quad \text { [Higher is better] }}\end{array}$ & 2.11 & 3.62 & 2.32 & & 1.48 & 3.38 & 2.35 & 3.12 \\
\hline $\begin{array}{l}\text { Average Video Total Download Rate } \\
\text { (kbps) } \\
\text { [Higher is better] }\end{array}$ & 1376.8 & 1822.8 & 1469.4 & & 1279.5 & 1802.0 & 1417.7 & 1843.3 \\
\hline $\begin{array}{l}\text { Average Video Maximum Download } \\
\text { Rate (kbps) }\end{array}$ & 6382.5 & 19150.2 & 6223.4 & 18434.1 & 4487.4 & 14386.2 & 6237.0 & 18353.7 \\
\hline $\begin{array}{r}\text { Average Initial Buffering Latency (ms) } \\
\text { [Lower is better] }\end{array}$ & 9513.9 & & 6760.6 & 1187.8 & 7842.9 & 1754.0 & 7046.2 & 1461.4 \\
\hline $\begin{array}{l}\text { Average Video E2E RTT Ping (ms) } \\
\text { [Lower is better] }\end{array}$ & 543.5 & & 348.8 & 44.4 & 244.2 & 66.7 & 353.5 & 60.8 \\
\hline $\begin{array}{l}\text { Average Total Re-buffering Latency } \\
\text { (ms) } \\
\text { [Loweris better] }\end{array}$ & 15513.2 & 4472.8 & 10273.5 & & 16907.0 & 4384.4 & 10843.5 & 25009.2 \\
\hline $\begin{array}{r}\text { Average Cellular Signal Strength (dBm) } \\
{[\text { Higheris better }]}\end{array}$ & -84.3 & -90.5 & -81.6 & -85.8 & -86.0 & -85.4 & -77.0 & -84.7 \\
\hline
\end{tabular}

(c)

\begin{tabular}{|c|c|c|c|c|c|c|c|c|}
\hline \multirow[t]{3}{*}{ Morphology: Suburban } & \multicolumn{4}{|c|}{ Operator: Z } & \multicolumn{4}{|c|}{ MBB service: VIDEO } \\
\hline & \multicolumn{2}{|c|}{ KV } & \multicolumn{2}{|c|}{ JOHOR } & \multicolumn{2}{|c|}{ SABAH } & \multicolumn{2}{|c|}{ SARAWAK } \\
\hline & $3 G$ & $4 G$ & $3 G$ & $4 G$ & $3 G$ & 4G & $3 G$ & $4 G$ \\
\hline $\begin{array}{c}\text { Initial Buffering Success Ratio } \\
\text { [Higheris better] }\end{array}$ & 0.95 & 1.00 & 0.93 & & 0.82 & & 0.96 & \\
\hline $\begin{array}{l}\text { Average vMOS Score } \\
[\text { Range }=1 \text { to } 5] \quad \text { [Higher is better }]\end{array}$ & 1.49 & 3.61 & & 3.59 & 1.80 & 3.40 & 1.85 & 3.48 \\
\hline $\begin{array}{l}\text { Average Video Total Download Rate } \\
\text { (kbps) } \\
\text { [Higheris better] }\end{array}$ & 1401.1 & 1821.7 & & 1812.2 & 1340.5 & 1839.3 & 1470.0 & 1813.5 \\
\hline $\begin{array}{l}\text { Average Video Maximum Download } \\
\text { Rate (kbps) }\end{array}$ & 6176.0 & & & 18275.1 & 5824.7 & 14594.6 & 6096.7 & 15281.8 \\
\hline $\begin{array}{r}\text { Average Initial Buffering Latency (ms) } \\
\text { [Lower is better] }\end{array}$ & 11783.2 & 1236.3 & & 1303.0 & 11006.3 & 1966.4 & 11011.3 & 1617.4 \\
\hline $\begin{array}{l}\text { Average Video E2E RTT Ping (ms) } \\
\text { [Lower is better] }\end{array}$ & 647.2 & 49.2 & & 43.2 & 581.7 & 95.7 & 739.2 & 70.2 \\
\hline $\begin{array}{l}\text { Average Total Re-buffering Latency } \\
\text { (ms) } \\
\text { [Loweris better] }\end{array}$ & 19846.6 & 3213.3 & & 2399.0 & 13585.6 & 7195.3 & 11483.3 & 2412.6 \\
\hline $\begin{array}{r}\text { Average Cellular Signal Strength (dBm) } \\
{[\text { Higheris better] }}\end{array}$ & -78.5 & -88.4 & -85.3 & -87.2 & -83.1 & -87.6 & -78.3 & \\
\hline
\end{tabular}


In short, we discovered better performance of $4 \mathrm{G}$ in comparison to $3 \mathrm{G}$ networks. $4 \mathrm{G}$ outshined $3 \mathrm{G}$ in services provided by all the 3 considered MNOs in each of the 4 states. Moreover, the application of all the 8 KPIs also indicated outperformance of $3 \mathrm{G}$ by $4 \mathrm{G}$ networks. However, $3 \mathrm{G}$ depicted better performance than $4 \mathrm{G}$ only in terms of average cellular signal strength. This calls for the extension of $4 \mathrm{G}$ coverage areas to render better signal strength to users. Moreover, all the 3MNOs depicted almost similar performance on application of all the $8 \mathrm{KPIs}$, for both networks and all 4 states.

\section{KEY FINDINGS}

The network performance measurement is evaluated in this study through the 4 metrics of coverage, latency, satisfaction, and speed. These factors affect the user experience while he avails various mobile broadband services. Coverage - It is defined as the strength of the cellular signal during video streaming and browsing activities. User experience is highly dependent on the coverage specifically when he wants to browse or download videos. Latency - it refers to the time taken for network response. It is evaluated as the delay in data transmission from source to device. Latency is specifically significant for users interested in video calls, games and browsing. Satisfaction - The network transmission speed affects the video and gaming activities; in case of low network transmission speed, the users experience difficulty in their gaming and video activities and hence, user satisfaction is low. Conversely the situation is reversed for high network transmission speed. This network transmission speed and the consequent satisfaction of the user may be evaluated through a metric called vMOS of mobile video services. The metric is evaluated using a 5-points scale. The scores of successfully downloaded games and videos determine the user experience and satisfaction. Speed -Speed is the rate at which data transfers from source to device. The download rate determines the rate of total rate of data transfer between source and device while the data throughput determines the amount of data transferred. According to the YouGov research, most of the users switch to $4 \mathrm{G}$ networks in anticipation of higher speed of internet browsing and faster video streaming. The user expects high speed net surfing matching to that of home broadband. In short, this factor is crucial for network performance. The main research findings have been given below:

\section{A. Performance In States}

From the obtained these results it can be stated that overall, the measured states in Malaysia, the all operators invest more for $4 \mathrm{G}$ technology in $\mathrm{KV}$ state much more as compared to the other suburban area in the measured states.

\section{B. Performance $O f 4 G$ and $3 G$ Networks}

$4 \mathrm{G}$ networks evidently outshined $3 \mathrm{G}$ networks in almost all aspects for each considered MNO in all the 4 states as evident in our results. This extraordinary performance by $4 \mathrm{G}$ networks for various MNOs in different states clearly indicate that the future of networking lies in $4 \mathrm{G}$ which can revolutionize the world of broadband services.

\section{Coverage}

The network coverage can be evaluated from the strength of received signal. Users can easily and quickly get access to MBB services when the coverage is wider and the signal is stronger. In order to avoid any bias in results, the distribution of signal strength will be assessed in different testing areas to get a better picture of network coverage. The data indicated that the $3 \mathrm{G}$ and $4 \mathrm{G}$ received signal strengths remained almost consistent across 3 considered $\mathrm{MNO}$ networks.

\section{Latency}

Latency is the network response time. Latency may be evaluated through a 'ping test' whereby the time taken by unit data to reach a point and respond to user's request is recorded. In case of web browsing and applications, the time taken for accessing and loading a requested webpage gives the web browsing speed. This speed depends on the response and latencies in page display. Users can experience better quality of video services, gaming and web browsing if the latency performance is better. The ping test results indicated the web ping average RTT latency of at least $42.4 \mathrm{~ms}$ for $4 \mathrm{G}$ network while a minimum of $69.9 \mathrm{~ms}$ for $3 \mathrm{G}$ network. Similarly, as low as $33.27 \mathrm{~ms}$ of the average E2E RTT ping server latency was recorded for $4 \mathrm{G}$ networks while a minimum of $122.98 \mathrm{~ms}$ was recorded for $3 \mathrm{G}$ network.

\section{E. Satisfaction}

User satisfaction (specifically for the users interested in webbrowsing and video streaming) is dependent on network performance in context of successful access to a webpage and undisrupted video streaming. In context of video services, stalling time and buffering time play an important part in network performance. The performance indicator vMOS gives a score ranging from 1 to 5 depending on the network performance with respect to stalling and buffering time such that higher vMOS score is allocated to better network performance. The outdoor drive test conducted at all the test areas indicated vMOS scores higher than 3 for $4 \mathrm{G}$ networks and lower than 3 for $3 \mathrm{G}$ networks. The scores indicated the network performance in context of both web browsing and video streaming.

\section{F. Speed}

Speed, as defined earlier indicates the rate and amount of data transfer between the source and the device on user's request. It is the rate of download of a video or web page. Speed may determine the time taken in accessing a webpage. According to YouGov's research, the main service availed by users in $4 \mathrm{G}$ network usually involves web browsing. This study indicated that the $4 \mathrm{G}$ network showed 4.2 times better performance than $3 \mathrm{G}$ network in terms of downloading speed in browsing activities while the $4 \mathrm{G}$ network showed 1.6 times better downloading speed in video streaming activities. 


\section{LIMITATION AND FUTURE DIRECTIONS}

In the current research, MBB services used for streaming videos and browsing websites have been analyzed for their performance levels and insights are presented. The research study scope does not include assessing the performance carrying out voice calls or sending the short message service (SMS). The limitations present in the present study as follows:

\section{A. Further KPIs}

1. In the present paper, the information stated is within the context of mobile broadband download speeds, web browsing speeds and latency. The research does not take into account consumer experience variables for making use of mobile services like billing, customer services, data allowances, traffic management policies, prices and others. Aspects such as text messaging, call quality, voice services and others have not been tested.

2. The research study may also integrate the analysis of the MBB networks performance when several combinations are being accessed like photo-and-video-based website contents, web-browsing and video-streaming testing applications, MBB networks and KPIs, and research area diversified suburban regions.

3. Within various operator networks, assessment can be made for the delay variation (jitter) parameters.

\section{B. Network Availability}

1. The mobile broadband service performance is highly dependent upon network availability and it is the serving network and smart phone which decides it. As the research does integrate coverage data, it does not analyze the network availability. This network availability depends upon various factors such as base station distance, keeping in mind that the user could be outdoors or in the building, or they could be in motion or stationery. For example, when the $3 \mathrm{G}$ technologies are locked into the smartphone, it would not indicate that there wouldn't be any $4 \mathrm{G}$ network coverage at that specific place and time.

2. Network availability plays a significant role in the MBB services performance levels. Even though, there is limited coverage data present within the current research, there is no analysis present on the network availability levels that are based upon various factors like the base station distance present, the user availability which may be outdoor or indoor and if the user has been in motion or remained stationery.

3. For the stated MNO, the present research doesn't take into account the network availability. For example, when the $4 \mathrm{G}$ network is connected to a device, it would not mean that there is unavailability of the $3 \mathrm{G}$ network. The present research method would not provide instructions to the device regarding the technology it must connect to at the time of the driving test.

4. Performance of service is also influenced by the amount of people, present in the same location, who are concurrently making use of the mobile network. This, along with the coverage fluctuations refers to the variation in the performance availability for the individual customers in terms of location as well as time.

5. The performance of MBB networks is also affected by the number of users present that may access the network system during the specific time period. Hence, the spatial-temporal aspects related to the user number for service access should be considered as a variable which is to be analyzed in the future research studies.

\section{Extension Of Testing}

1. There are only four states present in the current research and for the morphologies, the complete Malaysian performance has not been stated.

2. The performance of the MBB networks is influenced by the number of people who use the mobile network within the same location. Hence, for each individual customer, the performance would be different in terms of location and time. The present research can expand based on these aspects.

3. For the future, it is possible to analyze the MBB networks that are delivered to devices apart from smartphones along with the Virtual Mobile Network Operators (VMNOs).

4. When the $4 \mathrm{G} / 3 \mathrm{G}$ networks are accessed, when various mobile devices are used, it does not influence the experience of the user if the speed of the user is faster as compared to the channel speed. On the other hand, if the device speed is slower than the channel speed, then there will be a negative influence on the experience of the users. Generally, factors which influence the mobile browsing experience of the users are the state, websites, network infrastructure, browser application, mobile device and context of the user. The current research does not completely assess these factors.

5. There is a need for the time duration of the drive test to be longer. A larger area must be covered so that completion of measurements is possible. It is a timeconsuming approach.

6. At the time of the drive test, measurement devices should be used to download the measurement logs and for processing it should be uploaded. There is high data amount needed.

7. For the future research, there would be different morphologies applied for the analysis of the MBB performance, like indoors, and dense urban.

8. Not long from now, the MBB network performance of the rural areas will have to be enhanced further since there is drastic development in the MBB networks of these areas. This development is caused by the smart IoT application expansion like smart farms, smart grading, smart homes, and other smart solutions [28-31]. Hence, there is need for additional research and analysis for the rural area $5 \mathrm{G}$ network planning. 
9. There is limited research present upon the suburban areas within three Malaysian states. Hence, the MBB network performance cannot be generalized for the complete nation using the various morphologies.

\section{Inclusion Of GIS}

The geographical areas MBB services have correlation aspects which can be presented by the Geographical Information System (GIS) solutions. Their infrastructure and natural attributes are quite similar in nature. For the future, it sounds like a significant research topic as the service providers would be able to gain a thorough understanding of the rural areas MBB performance. Hence, the forecasting models built for the MBB performance would be realistic in nature.

\section{E. Mobility Management}

For future research, mobility management also seems to be an essential subject. The measurement information attained from the drive test can be used. Simulation has been used for all information presented earlier upon mobility management [3236]. Hence, now, by using the measurement data from the drive test, the researchers would be able to establish mobility management algorithms and models that are efficient in nature. Effective planning can be carried out by the regulators and operators for their mobile users, specifically for the ones in need of connections that are highly reliable.

\section{F. Handover}

The current research can be expanded by including handover problems taking place in the suburban regions over the heterogeneous networks. For the ultra-dense networks in the future, it would be highly recognized since the small base stations would increase in numbers and complexity in the network specifications would be observed. Hence, the mobility management problems would observe a drastic increase [34, 36-38].

\section{G. Propagation Study}

1. It is necessary to take into account several channel propagations influence like fading caused by rain, small scale fading, large scale fading and blockage. Within the current research, the measurement period was only of two months because of which the network performance has not been tested within altering climatic circumstances.

2. As the research has been carried out within the context of an outdoor localization system [39], it has been recommended that the methodology applied should be similar to the one earlier so that an efficient indoor localized system algorithm can be developed.

\section{H. Drive Test}

1. Measurement devices should be used for downloading of the measurement logs and uploading for processing at the time of the drive test. There is significant amount of data required.

2. It is quite costly to carry out the drive test solution since there is a need to integrate the vehicle rent, the fuel cost as well as the maintenance.

3. The time duration for the drive test should be long. The area covered must also be bigger so that a complete measurement is attained. Hence, the process becomes time consuming.

\section{Implementation of $5 G$}

1. From the current research, a measured data set has been attained which is now used for the prediction of latency, download speed, signal strength and others in real time. Through this information, the reliability of the $5 \mathrm{G}$ network in the future can be enhanced.

2. To effectively implement the $5 \mathrm{G}$ variables, it is necessary to analyze the trees. Along with trees, there are various issues which may could provide passive interference while detonating the link performance caused by rain or rest of the channel impairments due to long buildings.

3. The average latency in $5 \mathrm{G}$ networks is approximately $1 \mathrm{~ms}$. In order to understand the speed of this aspect, it should be considered that $10 \mathrm{~ms}$ are taken by the human eye to capture an image and process it in the brain. Hence, real-time critical applications like low latency or remote surgery would prove to be quite crucial. Later technologies and 5G advancements are very much dependent upon the latency performance. In the future, it would be essential to carry out research upon the $5 \mathrm{G}$ network latency using the drive test research. It would help analyze how real-time critical applications can be supported through this reliable new technology.

4. Lastly, when the 5G technology has been widely deployed in Malaysia, the present research may take into account the $5 \mathrm{G} \mathrm{MBB}$ service provider performance so that the superiority levels can be measured as compared to the earlier generations of MBB. This seems to be quite an interesting aspect as implementation is carried out using millimeter-wave bands with characteristics of cell size support that is small and path loss which is high [40-43].

\section{VIICONCLUSION}

Within the current research, the $4 \mathrm{G}$ and $3 \mathrm{G}$ mobile network performances of the Malaysian suburban morphology have been stated using drive test measurements. There are four variables applied for the assessment of the mobile network performance which are coverage, latency, satisfaction and speed. There are two kinds of MBB services being used and they are web browsing and video streaming. As part of the present research, the $4 \mathrm{G}$ and $3 \mathrm{G}$ technologies performances have been compared to three kinds of MNOs network present at four kinds of sites which are Klang Valley, Johor, Sarawak, and Sabah. Analysis suggests that, for all the three networks, as compared to the $3 \mathrm{G}$ networks, the $4 \mathrm{G}$ networks had a more 
efficient performance level on average. Additionally, for the suburban areas taken into account, the $4 \mathrm{G}$ networks have been deployed higher as compared to the $3 \mathrm{G}$ networks and this means that for the tested area, the dominant network present is 4G. For all mobile operators, this difference remained consistent. The current research would allow an upgrade of the current MBB networks within the Malaysian suburban areas for aiming to meet the enhanced $5 \mathrm{G}$ technology traffic demand. For the suburban areas, the results presented allow a general course for efficient planning of the $5 \mathrm{G}$ network.

\section{APPENDIX}

Appendixes, if needed, appear before the acknowledgment.

\section{ACKNOWLEDGMENT}

This research has been produced benefiting from the 2232 International Fellowship for Outstanding Researchers Program of TÜBİTAK (Project No: 118C276) conducted at Istanbul Technical University (ITU), Turkey. Meanwhile, the authors would like to acknowledge the support provided by the Ministry of Higher Education Malaysia (MOHE) under the Fundamental Research Grant Scheme (FRGS/1/2019/TK04/UTM/02/34). The work was also supported in part by Universiti Teknologi Malaysia (UTM) under the Collaborative Research Grant (CRG) of R.J130000.7351.4B468, and the Higher Institution Centre of Excellence (HICOE) Grants of R.J130000.7851.4J413 and R.J130000.7851.4J493.

\section{PHOTOBIOGRAPHY}

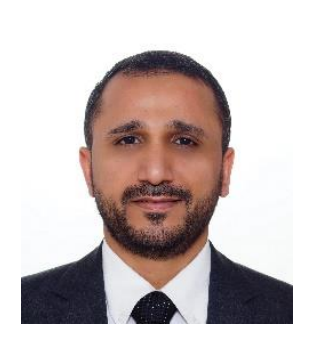

Ibraheem Shayea is working as an associate researcher from the 1st of September 2019 until now at Istanbul Technical University (ITU), Faculty of Electrical and Electronics Engineering, Department of Electronics \& Communications Engineering, Istanbul, Turkey. $\mathrm{He}$ is teaching courses for Master's and Bachelor's students. The key focuses of his research areas are on mobility management in future Heterogeneous $(4 \mathrm{G}, 5 \mathrm{G}$, and 6G) Networks, Mobile Edge Computing, Machine, and Deep Learning, Internet of things (IoT), Propagation of millimeter-wave, Mobile Broadband Technology and Future Data Traffic Growth and Spectrum Gap Analysis. He has published several scientific research Journals, conference papers, and whitepapers. He is running research projects with Postdoc researchers, Ph.D., and Master's students. He had worked from the 1st of September 2018 until 31 August 2019 as a Researcher Fellow at Istanbul Technical University (ITU), Istanbul, Turkey. From the 1st of January 2016 until 30 Jun 2018, he worked as a Postdoctoral Fellow at Wireless Communication Center (WCC), University of Technology Malaysia (UTM), Malaysia. From the 1st of January 2011 until 30 December 2015 (during his Ph.D. study), he worked as a Research Assistant and Demonstrator at the Department of Electrical, Electronic Engineering, Faculty of Engineering and Built Environment, Universiti Kebangsaan Malaysia (UKM), Malaysia. In December 2015, he received his Ph.D. in the field of Electrical \& Electronic Engineering, specifically in Wireless Communication Systems, from the Department of Electrical, Electronic Engineering, Faculty of Engineering and Built Environment, Universiti Kebangsaan Malaysia (UKM), Malaysia. In July 2010, he received his master's degree in Communication and Computer Engineering from the
Department of Electrical, Electronic Engineering, Faculty of Engineering and Built Environment at the Universiti Kebangsaan Malaysia (UKM), Malaysia. In July 2004 he got his degree, Bachelor in Electronics and Communication Engineering from the Faculty of Engineering, University of Diyala. From the 1st of July 2006 until 28, February, 2007 he worked as a Maintenance Manager at the company of Computer and Research Center (CRC) in Yemen. From the 1st of January, 2005 until 27 Jun 2006, he worked in Yemen as a Computer and Electronic maintenance engineer.

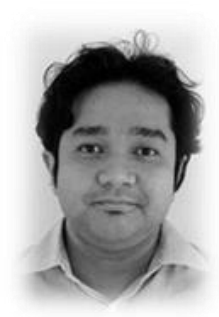

Marwan HadriAzmi received the B.Eng. (Hons Class I) degree in electrical and telecommunications from the UniversitiTeknologi Malaysia in 2003, the M.Sc degree in communications and signal processing from the Imperial College of Science, Technology and Medicine, University of London in 2005, and the Ph.D. degree from the University of New South Wales, Australia, in 2012. He is currently a senior lecturer at Wireless Communication Centre, UniversitiTeknologi Malaysia. From 2012 to 2014, he spent his Sabbatical leave of absence at the McGill University, Canada, working in the funded project by RIM Inc. and NSERC, entitled "Cooperative Spectrum Sensing and Information Relaying in Cognitive Wireless Communications". His research interests include mobile and wireless communications, communication theory, error control coding, relay networks, spectrum sensing for cognitive radio, and iterative receiver.

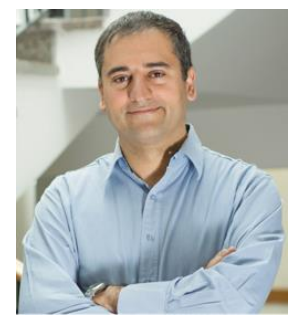

Mustafa Ergen is professor in Istanbul Technical University. Previously, he was in Turk Telekom as a Chief Technology Advisor. Earlier, Mustafa cofounded Silicon Valley startup WiChorus Inc. focusing $4 \mathrm{G}$ technologies and company is acquired by Tellabs [now Coriant]. He was earlier a National Semiconductor Fellow [now TI] at the University of California Berkeley, where he cofounded the Distributed Sensing Lab, focusing on statistical sensor intelligence and vehicular communication. Mustafa completed four programs from UC Berkeley: PhD and MS degrees in electrical engineering, MA degree from International Studies and MOT program from HAAS Business School. His BS is from electrical engineering as valedictorian from ODTU. Prof. Ergen has more than fifty patent applications, many publications and authored three books: "Mobile Broadband" and "Multi-Carrier Digital Communications" are about wireless communications and published from Springer. Last one is about entrepreneurship, titled "Entrepreneurial Capital: Silicon Valley History and Startup Economy", published by Alfa in Turkish. He is also founder of venture funded Ambeent Inc. focusing 5G WiFi and AI.

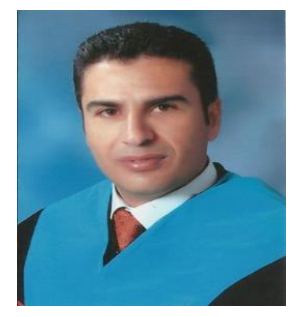

Yousef Ibrahim Daradkeh PhD., P.Eng., Doctor of Engineering Sciences in Computer Engineering and Information Technology (Computer Systems Engineering and Computer Software Engineering), is an Associate Professor at the Department of Computer Engineering and Networks, College of Engineering, Prince Sattam bin Abdulaziz University, KSA. He is a Senior Scientific Researcher and the Assistant Dean for Administrative Affairs. Dr. Daradkeh is a dynamic academician having more than 15 years of experience specializing in teaching and scientific research development and administration experience, He has taught wide spectrum of Computer Science, Computer Engineering and Networks, Computer Software Engineering Courses. Undergraduate and graduate. He has been working as a Post-Doctoral Research Fellow, Department of Electrical and Computer Engineering, University of Calgary, Canada. Dr. Daradkeh is a well-known and respected scientist internationally. $\mathrm{He}$ has an excellent experience in designing courses that bridge the gap between academia and industry as well as follow the accreditation requirements. He has published over 90 high quality refereed research papers in the international Journal and Conference, He has also published two books, one Chapter and an Edited Book in the most prestigious publications. He has Membership of The International Academy of Science and Engineering for Development (IASED). The international recognition of his scientific achievements is demonstrated by numerous invitations to participate in the 
program committees of international conferences and foreign journals, as well as lecturing at renowned scientific centers around the world.

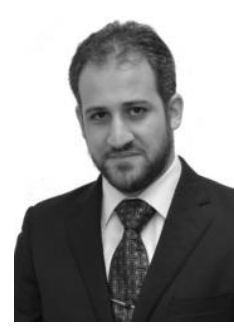

Ayman A. El-Saleh (M'13-SM'17) received his B.Sc. degree in Communications Engineering from Omar ElMukhtar University (OMU), Libya, in 1999, his M.Sc. in Microelectronics Engineering and his Ph.D. in Wireless Communications both from Universiti Kebangsaan Malaysia (UKM), in 2006 and 2012, respectively. He joined the Faculty of Engineering at Multimedia University (MMU) in October 2006 at which he was a Senior Lecturer and the Chairperson of Centre for Wireless Technology (CWT). In April 2017, he was appointed as the Lead of Connectivity Research Theme at MMU. He joined A'Sharqiyah University in Oman in September 2017 at which he is currently an Assistant Professor. He is also a Senior Member of IEEE, and was an Executive Committee Member of IEEE Malaysia ComSoc/VTS Joint Chapter in 2015 and 2016. He is a reviewer of several ISI-indexed journals and published about 60 journal and conference articles. His research interests include cognitive radio networks, heterogeneous LTE/LTE-Advanced cellular networks, and applications of artificial intelligence and evolutionary algorithms in wireless communications.

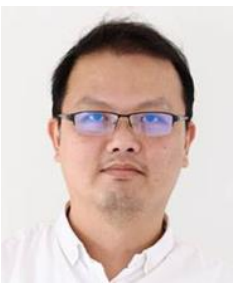

Tien Han Chua received both the B.Sc. (Honours) degree in Electrical engineering (First Class) and the Master of Electrical Engineering in Wireless Engineering from the Universiti Teknologi Malaysia in 2003 and 2007, respectively. Tien Han was a Tutor (2005-2007) and then a Lecturer (2007-present) at the Faculty of Electrical Engineering, Universiti Teknologi Malaysia. He is currently on a 3-year study leave to pursue a Ph.D degree at the Computer Laboratory, University of Cambridge. His research interests include broadband fixed wireless access systems, radio propagation, channel modelling and measurement.

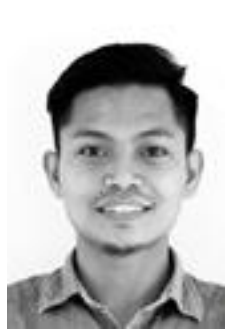

Arsany Arsad is a Research Officer in Wireless Communication Centre (WCC), Universiti Teknologi Malaysia (UTM) International Campus Kuala Lumpur. $\mathrm{He}$ obtained his B.Eng in Electrical Telecommunication and M.Eng Electrical from UTM Johor Bahru in 2009 and 2013 respectively. His research interests are radio propagation and mobile wireless communication. He actively involved in university research projects and collaboration as well as consultation projects with industry.

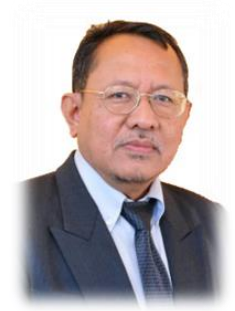

Tharek Abd Rahman is a Professor at Faculty of Electrical Engineering, Universiti Teknologi Malaysia (UTM). He obtained his BSc. in Electrical \& Electronic Engineering from University of Strathclyde UK in 1979, $\mathrm{MSc}$ in Communication Engineering from UMIST Manchester UK and $\mathrm{PhD}$ in Mobile Radio Communication Engineering from University of Bristol, UK in 1988. He is the Director of Wireless Communication Centre (WCC), UTM. His research interests are radio propagation, antenna and RF design and indoors and outdoors wireless communication. He has also conducted various short courses related to mobile and satellite communication to the Telecommunication Industry and Government body since 1990 . He has a teaching experience in the area of mobile radio, wireless communication system and satellite communication. He has published more than 120 papers related to wireless communication in national/international journal and conference.

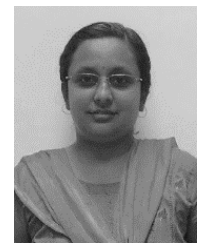

Dr. Dalia Nandi is presently working as Assistant Professor at Indian Institute of Information Technology Kalyani, India. She passed B.Sc with Electronics honours from University of Calcutta and stood first class first. She has taken her B.Tech and M.tech degree from Institute of Radio Physics and Electronics, University of Calcutta. She did her Ph.D. in Radio Physics and Electronics from
Institute of Radio Physics and Electronics, University of Calcutta. She has 30 publications to her credit in journals, conference proceedings. She is senior member of IEEE. Her research interests include 5G communication, radio wave propagation, remote sensing, atmospheric and space sciences etc.

\section{REFERENCES}

[1] R. Atat, L. Liu, J. Wu, G. Li, C. Ye, and Y. Yang, "Big data meet cyber-physical systems: A panoramic survey," IEEE Access, vol. 6, pp. 73603-73636, 2018.

[2] R. N. Mitra and D. P. Agrawal, "5G mobile technology: A survey," ICT Express, vol. 1, pp. 132-137, 2015.

[3] O. Alay, A. Lutu, D. Ros, R. Garcia, V. Mancuso, A. F. Hansen, et al., "MONROE: Measuring mobile broadband networks in Europe," in Proceedings of the IRTF \& ISOC Workshop on Research and Applications of Internet Measurements (RAIM), 2015.

[4] P. Preston, A. Cawley, and M. Metykova, "Broadband and rural areas in the EU: From technology to applications and use," Telecommunications Policy, vol. 31, pp. 389-400, 2007.

[5] R. Mason and F. Rennie, "Broadband: A solution for rural eLearning?," The international review of Research in Open and Distributed Learning, vol. 5, 2004.

[6] M. Kojo, J. Griner, and Z. Shelby, "Performance enhancing proxies intended to mitigate link-related degradations," 2001.

[7] OOKLA. (2020, 10 May 2020). OOKLA. Available: http://www.speedtest.net/

[8] C. Kreibich, N. Weaver, B. Nechaev, and V. Paxson, "Netalyzr: Illuminating the edge network," in Proceedings of the 10th ACM SIGCOMM conference on Internet measurement, 2010, pp. 246-259.

[9] J. Gozalvez and J. Dunlop, "On the importance of using appropriate link-to-system level interfaces for the study of link adaptation," in Proceedings of the IST Mobile \& Wireless Communications Summit, 2003, pp. 441-445.

[10] L. Zuliani, C. Gambetti, A. Zanella, and O. Andrisano, "Link level aspects modelling in the simulation of packet switched wireless networks," in IEEE Wireless Communications and Networking Conference, 2006. WCNC 2006., 2006, pp. 723728.

[11] A. Ozovehe and A. Usman, "Performance analysis of GSM networks in Minna Metropolis of Nigeria," Nigerian Journal of Technology, vol. 34, pp. 359-367, 2015.

[12] F. Afroz, R. Subramanian, R. Heidary, K. Sandrasegaran, and S. Ahmed, "SINR, RSRP, RSSI and RSRQ measurements in long term evolution networks," International Journal of Wireless \& Mobile Networks, 2015.

[13] M. R. Tanhatalab, S. M. J. J. Jadeh, and A. O. Esfahani, "Practical schemes for throughput improvement in live networks," in 2017 International Conference on Signals and Systems (ICSigSys), 2017, pp. 239-244.

[14] J. Parikh and A. Basu, "Effect on System Performance due to Upgradation of $2 \mathrm{G} / 3 \mathrm{G}$ System to LTE," International Journal of Wireless and Microwave Technologies (IJWMT), vol. 6, p. 11, 2016.

[15] I. Petruţ, R. Poenar, M. Oteşteanu, C. Balint, and G. Budura, "User Experience Analysis on Real 3G/4G Wireless Networks," 2015.

[16] N. F. Ab Aziz, M. Ali, and N. Azian, "4G Coverage in Malaysia," International Journal of Science and Research (IJSR), vol. 4, pp. 1817-1823, 2015.

[17] Y.-C. Chen, E. M. Nahum, R. J. Gibbens, D. Towsley, and Y.-s. Lim, "Characterizing 4g and 3g networks: Supporting mobility with multi-path tcp," University of Massachusetts Amherst, Tech. Rep, 2012. 
[18] B. K. Engiz and Ç. Kurnaz, "Comparison of Signal Strengths of $2 \mathrm{G} / 3 \mathrm{G} / 4 \mathrm{G}$ services on a University Campus," International Journal of Applied Mathematics, Electronics and Computer, vol. 4, pp. 37-42, 2016.

[19] S.-p. Yeh, S. Talwar, S.-c. Lee, and H. Kim, "WiMAX femtocells: a perspective on network architecture, capacity, and coverage," IEEE Communications Magazine, vol. 46, pp. $58-65,2008$.

[20] K. Pahlavan, X. Li, and J.-P. Makela, "Indoor geolocation science and technology," IEEE Communications Magazine, vol. 40, pp. 112-118, 2002.

[21] N. N. N. B. Jefri, K. Anuar, and S. Arjunan, "Real time indoor measurement of $2 \mathrm{G}, 3 \mathrm{G}$ and LTE mobile networks in Malaysia," in 2016 IEEE 3rd International Symposium on Telecommunication Technologies (ISTT), 2016, pp. 19-24.

[22] A. Imoize and O. Adegbite, "Measurements-Based Performance Analysis of a 4G LTE Network in and around Shopping Malls and Campus Environments in Lagos Nigeria," Arid Zone Journal of Engineering, Technology and Environment, vol. 14, pp. 208-225, 2018.

[23] R. Nordin, A. H. Kelechi, M. H. Easa, S. Ahmad, and S. Musleh, "Empirical Study on Performance Evaluation Between Long Term Evolution (LTE), Third Generation (3G) and TV White Space Availability for Wireless Campus Network," International Journal of Simulation: Systems, Science and Technology, vol. 17, 2016.

[24] A. S. Khatouni, M. Mellia, M. A. Marsan, S. Alfredsson, J. Karlsson, A. Brunstrom, et al., "Speedtest-like measurements in $3 \mathrm{~g} / 4 \mathrm{~g}$ networks: The monroe experience," in 2017 29th International Teletraffic Congress (ITC 29), 2017, pp. 169177.

[25] I. Shayea, M. Ergen, M. H. Azmi, D. Nandi, A. A. El-Salah, and A. Zahedi, "Performance analysis of mobile broadband networks with $5 \mathrm{G}$ trends and beyond: Rural areas scope in Malaysia," IEEE Access, vol. 8, pp. 65211-65229, 2020.

[26] I. Shayea, T. A. Rahman, M. H. Azmi, C. T. Han, and A. Arsad, "Indoor network signal coverage of mobile telecommunication networks in West Malaysia: Selangor and Johor Bahru," in 2017 IEEE 13th Malaysia International Conference on Communications (MICC), 2017, pp. 288-293.

[27] I. Shayea, M. H. Azmi, M. Ergen, A. A. El-Saleh, C. T. Han, A. Arsad, et al., "Performance analysis of mobile broadband networks with $5 \mathrm{~g}$ trends and beyond: Urban areas scope in malaysia," IEEE Access, vol. 9, pp. 90767-90794, 2021.

[28] J. E. Prieger, "The broadband digital divide and the economic benefits of mobile broadband for rural areas," Telecommunications Policy, vol. 37, pp. 483-502, 2013.

[29] J. Ishmael, S. Bury, D. Pezaros, and N. Race, "Deploying rural community wireless mesh networks," IEEE Internet Computing, vol. 12, pp. 22-29, 2008.

[30] L. Galloway, "Can broadband access rescue the rural economy?," Journal of Small Business and Enterprise Development, vol. 14, pp. 641-653, 2007.

[31] G. Zhang, K. Li, D. Gu, X. Wang, X. Yang, K. Zhu, et al., "Visualizing knowledge evolution and hotspots of rural environment and health: A systematic review and research direction," IEEE Access, 2019.

[32] I. Shayea, M. Ismail, R. Nordin, H. Mohamad, T. Abd Rahman, and N. F. Abdullah, "Novel Handover Optimization with a Coordinated Contiguous Carrier Aggregation Deployment Scenario in LTE-Advanced Systems," Mobile Information Systems, vol. 2016, 2016.

[33] A. Alhammadi, M. Roslee, M. Y. Alias, I. Shayea, and S. Alraih, "Dynamic handover control parameters for LTEA/5G mobile communications," in 2018 Advances in Wireless and Optical Communications (RTUWO), 2018, pp. 39-44.
[34] A. Alhammadi, M. Roslee, M. Y. Alias, I. Shayea, S. Alraih, and K. S. Mohamed, "Auto Tuning Self-Optimization Algorithm for Mobility Management in LTE-A and 5G HetNets," IEEE Access, vol. 8, pp. 294-304, 2019.

[35] A. Alhammadi, M. Roslee, M. Y. Alias, I. Shayea, S. Alriah, and A. B. Abas, "Advanced Handover Self-optimization Approach for 4G/5G HetNets Using Weighted Fuzzy Logic Control," in 2019 15th International Conference on Telecommunications (ConTEL), 2019, pp. 1-6.

[36] I. Shayea, M. Ismail, R. Nordin, M. Ergen, N. Ahmad, N. F. Abdullah, et al., "New weight function for adapting handover margin level over contiguous carrier aggregation deployment scenarios in LTE-advanced system," Wireless Personal Communications, vol. 108, pp. 1179-1199, 2019.

[37] I. Shayea, M. Ergen, M. H. Azmi, and e. al., "Mobility Management in 5G Networks: A Survey on Key Challenges Drivers and Solutions "IEEE Access, 2020.

[38] A. Alhammadi, M. Roslee, M. Y. Alias, I. Shayea, and A. Alquhali, "Velocity-Aware Handover Self-Optimization Management for Next Generation Networks," Applied Sciences, vol. 10, p. 1354, 2020.

[39] S. Alraih, A. Alhammadi, I. Shayea, and A. M. Al-Samman, "Improving accuracy in indoor localization system using fingerprinting technique," in 2017 International Conference on Information and Communication Technology Convergence (ICTC), 2017, pp. 274-277.

[40] I. Shayea, T. A. Rahman, M. H. Azmi, and M. R. Islam, "Real Measurement Study for Rain Rate and Rain Attenuation Conducted Over $26 \mathrm{GHz}$ Microwave 5G Link System in Malaysia," IEEE Access, vol. 6, pp. 19044-19064, 2018.

[41] I. Shayea, T. Abd. Rahman, M. Hadri Azmi, and A. Arsad, "Rain attenuation of millimetre wave above $10 \mathrm{GHz}$ for terrestrial links in tropical regions," Transactions on Emerging Telecommunications Technologies, vol. 29, p. e3450, 2018

[42] I. Shayea, L. A. Nissirat, M. A. Nisirat, A. Alsamawi, T. A. Rahman, M. H. Azmi, et al., "Rain attenuation and worst month statistics verification and modeling for $5 \mathrm{G}$ radio link system at $26 \mathrm{GHz}$ in Malaysia," Transactions on Emerging Telecommunications Technologies, 2019.

[43] A. M. Al-Samman, T. A. Rahman, M. H. Azmi, and I. Shayea, "Path Loss Model and Channel Capacity for UWBMIMO Channel in Outdoor Environment," Wireless Personal Communications, pp. 1-11, 2019. 